\title{
$1 \quad$ CREB repressor in mushroom body enhances Drosophila LTM formation
}

2 Authors

3 Chun-Chao Chen, ${ }^{1, *}$ Hsuan-Wen Lin, ${ }^{1}$ Kuan-Lin Feng, ${ }^{2}$ Ruei-Yu Jhang, ${ }^{1,3}$ Linyi Chen, ${ }^{1,3}$ J. Steven

4 de Belle $e^{4,5,6}$, Tim Tully, ${ }^{1,2 *}$ and Ann-Shyn Chiang, $1,2,7,8,9,10^{*}$

5

\section{Affiliations}

${ }^{1}$ Brain Research Center, National Tsing Hua University, Hsinchu 30013, Taiwan.

${ }^{2}$ Institute of Systems Neuroscience and Department of Life Science, National Tsing Hua

University, Hsinchu 30013, Taiwan.

${ }^{3}$ Department of Medical Science and Institute of Molecular Medicine, National Tsing Hua University, Hsinchu 30013, Taiwan.

${ }^{4}$ Department of Psychological Sciences, University of San Diego, San Diego, CA, USA.

${ }^{5}$ School of Life Sciences, University of Nevada, Las Vegas, NV, USA.

${ }^{6}$ Acrovirt LLC, Las Vegas, NV, USA.

${ }^{7}$ Kaohsiung Medical University, Kaohsiung 80708, Taiwan.

${ }^{8}$ National Health Research Institutes, Zhunan 35053, Taiwan.

${ }^{9}$ China Medical University, TaiChung 40402, Taiwan.

${ }^{10}$ Kavli Institute for Brain and Mind, University of California at San Diego, La Jolla, CA 920930526, USA.

*Correspondence should be addressed to C.C.C (chenchunchao@gapp.nthu.edu.tw), T.T. (ttully@gapp.nthu.edu.tw) or A.S.C. (aschiang@life.nthu.edu.tw). 


\section{Abstract}

37 Long-term memory (LTM) requires learning-induced synthesis of new proteins allocated to specific 38 neurons and synapses in a neural circuit. Not all learned information, however, becomes permanent 39 memory. How the brain gates relevant information into LTM remains unclear. In Drosophila adults, 40 a single training session in an olfactory aversive task is not sufficient to induce protein synthesis41 dependent LTM. Instead, multiple spaced training sessions are required. Here, we report that initial 42 learning induces neural activity in the early $\alpha / \beta$ subset of Kenyon cells of the mushroom body (MB), 43 and output from these neurons inhibits LTM formation. Specifically in response to spaced training, 44 Schnurri activates CREBB expression which then appears to suppress the inhibitory output from 45 MB. One training session can enhance LTM formation when this inhibitory effect is relieved. We 46 propose that learning-induced protein synthesis and spaced training-induced CREBB act 47 antagonistically to modulate output from early $\alpha / \beta$ MB neurons during LTM formation. 


\section{MAIN TEXT}

\section{Introduction}

Drosophila continues to demonstrate its utility as a model system to study memory, more than four decades after the first mutant was described (Dudai et al., 1976). Genetic dissection of olfactory aversive memory formation using various single-gene mutants has revealed at the behavioral level several distinct temporal phases, including short-term memory (STM), middleterm memory (MTM), anesthesia-resistant memory (ARM) and long-term memory (LTM) (Tully et al., 1994; Tully et al., 1990; Tully, 1996; Quinn and Dudai, 1976). The initial learning event (acquisition) after a single training session (1x) appears to induce STM, MTM and ARM, while spaced training (10 training sessions with 15 min rest intervals between each, 10xS) appears uniquely required to induce LTM consolidation. Manipulations of several of these "memory genes" also have established cases where memory formation is either impaired or enhanced, revealing bidirectional biochemical modulation of memory formation (Yin et al., 1994; Yin et al., 1995a; Ge et al., 2004; Presente et al., 2004; Wu et al., 2007; Pavlopoulos et al., 2008; Huang et al., 2012; Tubon et al., 2013; Fropf et al., 2014; Lee et al., 2018; Scheunemann et al., 2018).

As the neural substrates of olfactory memory formation are elucidated in flies, a remarkable "memory circuit" is emerging. Olfactory information delivered from the antennal lobe (AL) by projection neurons $(\mathrm{PN})$ and foot shock reinforcement delivered by dopaminergic neurons (DAN) both converge on mushroom body (MB) neurons in the central brain where their coincidence triggers cascading cellular events that underlie learning (Dubnau and Chiang 2013; Perisse et al., 2013; Davis, 2015; Cognigni et al., 2018). MBs play a predominant role in subsequent memory formation, together with several groups of extrinsic MB neurons. Sequential genetically-defined memory phases map onto distinct subpopulations of these neurons. STM involves $\gamma, \alpha^{\prime} / \beta^{\prime}$ and $\alpha / \beta$ neurons and two classes of MB output neurons (MBON: MB-M4, MB-M6) (Blum et al., 2009; Scheunemann et al., 2012; Bouzaiane et al., 2015). MTM involves neural activity in $\gamma$, 
$\alpha / \beta$ and MB-V2 neurons (Blum et al., 2009; Scheunemann et al., 2012; Bouzaiane et al., 2015).

ARM requires neural activity in $\mathrm{MB} \gamma, \alpha^{\prime} / \beta^{\prime}, \alpha / \beta$ neurons, dorsal paired medial (DPM) neurons, anterior paired lateral (APL) neurons, DAN and four different MB output neurons (MB-M4, MB-

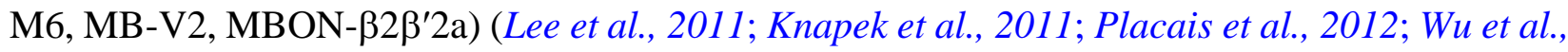
2013; Bouzaiane et al., 2015; Yang et al., 2016; Scholz-Kornehl and Schwärzel, 2016; Kotoula et al., 2017; Shyu et al., 2019). LTM involves neural activity in late MB $\alpha / \beta$ neurons with output from DPM, serotonergic projection neurons (SPN) and three classes of MBONs (MB-V3, MB-M4, MBON- $\left.\gamma 3, \gamma 3 \beta^{\prime} 1\right)$. Cyclic AMP response element binding protein (CREB)-dependent consolidation of LTM also requires activity in dorsal anterior lateral (DAL) neurons (Chen et al., 2012; Pai et al., 2013; Tonoki and Davis 2015; Bouzaiane et al., 2015; Wu et al., 2017; Scheunemann et al., 2018). Finally, memory retrieval depends on neural activity in DAL, pioneer $\alpha / \beta$ neurons and four classes

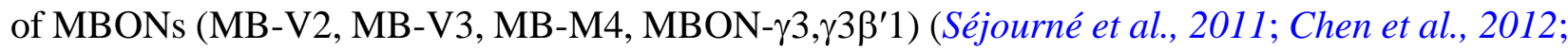
Pai et al., 2013; Bouzaiane et al., 2015; Wu et al., 2017).

Here, we describe another enlightening property of olfactory memory in Drosophila: inhibition of LTM formation at the circuit level. Output from the early $\alpha / \beta$ subpopulation of MB neurons appears initially to inhibit LTM formation, but with spaced training, transcription of $c r e b B$ (dcreb2, repressor) is induced therein, apparently reducing neural output therefrom and thereby enabling LTM formation. Thus, persistent olfactory memory formation appears modulated or "gated" at the level of neural activity in early $\alpha / \beta$ MB neurons. These observations presage the need for a more general deconvolution of biochemical mechanisms into distinct neuronal subtypes within a memory circuit.

\section{Results}

Learning inhibits LTM 
Sixty of the single-gene mutants mentioned above were generated using transposon mutagenesis and were screened for impairments of memory one day after 10xS training (Dubnau et al., 2003).

Twenty-two of these lines carried P-Gal4 enhancer traps, which enabled us to drive targeted inducible expression of a temperature-sensitive $\operatorname{Ricin}^{C S}$ transgene and then block protein synthesis after 10xS (Chen et al., 2012; Pai et al., 2013; Wu et al., 2017). With protein synthesis inhibited in this manner, we found impairments of 1-day memory in nine of these lines (figure supplement 1AC; table supplement 1) (Tully et al., 1994; Yin et al., 1994). Remarkably, GFP was expressed in DAL neurons in all nine cases (figure supplement 1B), an observation that contributed to our characterization of DAL neurons extrinsic to the MB as bona fide "LTM neurons" (Chen et al., 2012). Two of the enhancer-trap memory mutants that we screened were particularly informative. In umnitza flies, GFP was expressed in DAL neurons but very weakly in MB, and 1-day memory after 10xS was impaired. Conversely in norka flies, GFP was expressed in MB but not in DAL neurons and 1-day memory after 10xS was normal.

What then might be going on in the seven enhancer-trap mutants with normal memory and with GFP expression in both MB \& DAL neurons (Figure 1A; figure supplement 1A)? First, we confirmed that active Ricin ${ }^{\mathrm{CS}}$ inhibition of protein synthesis in different subsets of MB neurons did not impair 1-day memory after 10xS (figure supplement 2A-B and 3). In contrast, 1-day memory after 10xS was impaired by active Ricin ${ }^{\mathrm{CS}}$ in DAL or MB-V3 neurons (Chen et al., 2012; Pai et al., 2013; Wu et al., 2017) but was normal after massed training (10x training sessions with no rest intervals; $10 x \mathrm{M})$ or in control flies with inactive $\operatorname{Ricin}^{\mathrm{CS}}\left(18^{\circ} \mathrm{C}\right)$ (figure supplement 3$)$.

We next tested the hypothesis that inhibition of protein synthesis in MB might enhance LTM formation, thereby off-setting the impairment produced by blocking protein synthesis in DAL neurons. Using cry-Gal80 or MB-Gal80, we blocked transgenic Ricin ${ }^{\mathrm{CS}}$ expression outside (i.e. DAL neurons) or inside of MB, respectively, in these seven enhancer-trap memory lines (Figure 
1B-C) and then subjected them to suboptimal 3xS training. Surprisingly, LTM formation was enhanced in all seven lines by cry-Gal80 subtraction (Figure 1D-F).

The MB is composed of approximately 2,500 intrinsic neurons (Kenyon cells; KCs) developmentally derived from four neuroblasts and distinguished by their projections that form the $\gamma, \alpha^{\prime} / \beta^{\prime}$ and $\alpha / \beta$ lobes (Ito et al., 1997; Zhu et al., 2003; Lin et al., 2007). We looked among these neuronal subpopulations to identify where LTM enhancement might reside (Figure 2; figure supplement 2A). Active Ricin was expressed in all KCs or in $\gamma, \alpha^{\prime} / \beta^{\prime}$, or $\alpha / \beta$ neurons separately. Enhanced LTM was observed after 3xS only in $\alpha / \beta$ neurons, which were previously shown to have a role in LTM formation (Blum et al., 2009; Yu et al., 2006) (Figure 2A).

The $\alpha / \beta$ neurons are subdivided further into three types: pioneer $\alpha / \beta$, early $\alpha / \beta$ and late $\alpha / \beta$ neurons based on their birth sequences (Zhu et al., 2003; Lin et al., 2007; Tanaka et al., 2008; Aso et al., 2014). When active Ricin was expressed in these three subpopulations separately, we observed enhanced LTM after 3xS only when protein synthesis was blocked in early $\alpha / \beta$ neurons (Figure 2A, left). Enhanced LTM lasted for at least 4 days (Figure 2A, right) and was not observed in control flies (inactive Ricin ${ }^{\mathrm{CS}}$ ) after $3 \times \mathrm{S}$ training or in flies with active Ricin ${ }^{\mathrm{CS}}$ after $3 \mathrm{xM}$ (figure supplement $2 \mathrm{C}$ ). Blocking protein synthesis in early $\alpha / \beta$ neurons enhanced 1 - and 4 -day memories even after only 1x training (Figure 2B). Notably, LTM enhancement after 1x training required two copies of transgenic Ricin ${ }^{\mathrm{CS}}$. Together, these results indicate that inhibition of protein synthesis in early $\alpha / \beta$ neurons yields a bona fide enhancement of LTM formation.

We next inquired about the most effective time after training when inhibition of protein synthesis would enhance LTM. Ricin ${ }^{\mathrm{CS}}$ in early $\alpha / \beta$ neurons was activated for $12 \mathrm{~h}$ in a series of time windows staggered by $2 \mathrm{~h}$ during the first $24 \mathrm{~h}$ after $1 \mathrm{x}$ training (Chen et al., 2012; Wu et al., 2017). LTM was enhanced when protein synthesis was blocked beginning from 0- to 4-h but not from 6to 12 -h after training (Figure $3 \mathrm{~A}$ ). Shortening the inhibition period to $3 \mathrm{~h}$, we resolved the window of protein-synthesis-dependent LTM inhibition to the first $6 \mathrm{~h}$ after training (Figure 3B). 


\section{Output from early $\alpha / \beta$ neurons inhibits LTM}

To address whether the inhibitory effect on LTM in early $\alpha / \beta$ lobes depends on their neural output, we blocked synaptic transmission from pioneer $\alpha / \beta$, late $\alpha / \beta$ or early $\alpha / \beta$ neurons using $U A S$-shits (Dubnau et al., 2001; McGuire et al., 2001). In these experiments we found that 1- and 4-day memory after $3 \mathrm{xS}$ training were enhanced by this manipulation in early $\alpha / \beta$ (Figure $4 \mathrm{~A}-\mathrm{B}$ ), but not in pioneer or in late $\alpha / \beta$ neurons (figure supplement 4A). Interestingly, we also established that LTM after 3xS was enhanced when synaptic transmission was blocked from early $\alpha / \beta$ during the first $8 \mathrm{~h}$ period after training but not 9-24 h after training or during 1-day memory retrieval (Figure 4A). Thus, this temporal requirement for synaptic transmission from early $\alpha / \beta$ neurons corresponds to the requirement for protein synthesis (Figure 3). We confirmed these results using two additional Gal4 drivers expressing specifically in early $\alpha / \beta$ neurons (Figure $4 \mathrm{C}$; figure supplement $2 \mathrm{~A}$ ) and observed normal 1-day memory after 3xM (Figure 4B, middle) as in control flies carrying $U A S$ $s h i^{t s}$ alone, Gal4 alone (Figure 4B, right) or at the permissive temperature for $s h i^{t s}$ (Figure 4A, left and $4 \mathrm{C}$, right). Finally, we established that LTM after 10xS training was not impaired when neural output from early $\alpha / \beta$ neurons was blocked (figure supplement $4 \mathrm{~B}$ ). Together, these results indicate that, in the absence of spaced training, neural output from early $\alpha / \beta$ neurons inhibits LTM formation.

To examine the influence of early $\alpha / \beta$ neuron membrane excitability on memory, we used ectopic expression of either transgenic hyperexcitors $\left(U A S-S h a w^{D N}\right.$, a dominant-negative Shaw potassium channel and $U A S-N a C h B a c$, a sodium channel) or hypoexcitors (UAS-Shaw, a Shaw potassium channel and UAS-Kir2.1::GFP, an inward-rectifying potassium channel Venken et al., 2011). Temporal control of these transgenes was enabled using a tub-Gal80 $0^{\text {ts }}$ transgene (conditional expression of Gal80 suppresses Gal4 expression at $18{ }^{\circ} \mathrm{C}$ but not at $30^{\circ} \mathrm{C}$ McGuire et al., 2003). We found that increasing membrane excitability of early $\alpha / \beta$ neurons impaired 1 -day memory after 
10xS training (Figure 5A, left) without affecting (1) memory after 1x training (fig. S5A), (2) 1-day memory after 10xM training (figure supplement 5B) or (3) 1-day memory after 10xS training when flies were kept at permissive temperature $\left(18^{\circ} \mathrm{C}\right)$ (figure supplement $\left.5 \mathrm{C}\right)$. This inhibitory effect appears to be complete, because inhibition of protein synthesis by feeding flies cycloheximide (CXM) did not further reduce 1-day LTM after 10xS training (Figure 5A, right). Decreasing membrane excitability of early $\alpha / \beta$ neurons with ectopic expression of hypoexciter transgenes, on the other hand, enhanced both 1- and 4-day memory after 1x training (Figure 5B, left and middle), whereas enhancement of 1-day memory was not observed in control transgenic flies kept at the permissive temperature $\left(18^{\circ} \mathrm{C}\right)$ (Figure $5 \mathrm{~B}$, right). We also found normal 1-day memory in these transgenic flies after 10xS training (Figure 5C). Thus, sufficient spaced training appeared to occlude the enhancing effects on LTM formation of decreased membrane excitability in early $\alpha / \beta$ neurons. These data further support the notion that neural activity from early $\alpha / \beta$ neurons inhibits LTM formation downstream (Dubnau and Chiang 2013; Pai, et al., 2013; Wu et al., 2017).

\section{cAMP signaling in early $\alpha / \beta$ neurons enhances LTM}

Neural excitability is suggested to be modulated by cAMP signaling (Davis et al., 1998; Baines, 2003), which in MB is also involved in LTM formation (Blum et al., 2009). Accordingly, we inducibly overexpressed rutabaga ${ }^{+}\left(\right.$rut $\left.^{+}\right)$adenylyl cyclase (AC) or constitutively active $c A M P$ dependent protein kinase $\left(P k a^{a c t l}\right)$ transgenes in early $\alpha / \beta$ neurons and found that 1 -day memory after 1x training was enhanced to levels normally seen after 10xS in both cases (Figure 6A and 7A). Moreover, inducible RNAi knockdowns of these genes impaired 1-day memory after 10xS (Figure $6 \mathrm{~b}$ and $7 \mathrm{~b}$; figure supplement 6 ). Together, these results suggest that LTM formation is also modulated by cAMP in early $\alpha / \beta$ neurons.

\section{CREBB in early $\alpha / \beta$ neurons enhances LTM}


208 Protein synthesis-dependent LTM formation also depends on CREBB transcription factors, and 209 expression of CREBB protein is thought to be dependent on the expression level of protein kinases 210 involved in cAMP signaling (Lee et al., 2018). Consistent with our Rutabaga and PKA knockdown

211 results, we induced RNAi knockdown of CREBB in early $\alpha / \beta$ neurons and observed impairment 212 of 1-day memory after 10xS training. Further impairment was not seen in combination with 213 systemic protein synthesis inhibition by feeding CXM (Figure 8C). Because inhibition of protein 214 synthesis in early $\alpha / \beta$ neurons instead produced an enhancing effect on LTM formation, we 215 inducibly expressed crebB repressor-transgenes (Zhang et al., 2019) in these neurons only, with the 216 expectation that the manipulations would lead to enhanced memory. Indeed, expressing $c r e b B$ 217 enhanced 1-day memory after 1x training to levels normally seen after 10xS training (Figure 8A218 B; figure supplement 6).

Spaced training induces crebB transcription

We next generated a $c r e b B$ promoter-driven Gal4 transgene containing an 11-kb 5' genomic sequence just upstream of CREBB (see Methods) (Yin et. al., 1995b). This crebB-Gal4 drives GFP expression in most glia cells and brain neurons, including most MB neurons, though higher levels of expression can be seen in $\alpha / \beta$ compared to $\alpha^{\prime} / \beta^{\prime}$ or $\gamma$ neurons (Figure $9 \mathrm{~A}$ ). By photo converting pre-existing green KAEDE to red prior to training (Chen et. al., 2012), we measured significantly more newly synthesized $c r e b B$-Gal4 green KAEDE in the MB $\alpha$-lobe during 24-h intervals after $5 \mathrm{xS}$ or $10 \mathrm{xS}$ training, but not after $1 \mathrm{x}$ training or $10 \mathrm{xM}$ training in comparison with naïve control flies (Figure 9B-C). This training-induced increase in $c r e b B$ KAEDE appeared specific to the MB neurons because spaced training did not significantly change the levels of new $\operatorname{crebB}$ KAEDE in ellipsoid body (EB) or glia (Figure 9B, right). These results demonstrate that multiple sessions of 
protein synthesis in early $\alpha / \beta$ neurons enhanced LTM formation (Figure 1-3) suggests that crebB gene products function to repress protein synthesis.

\section{Schnurri (Shn) regulates CREBB-dependent LTM formation}

How does spaced training induce CREBB expression? To address this question, we sought to identify positive regulators of $c r e b B$ transcription during LTM formation. Yeast two-hybrid and chromatin immunoprecipitation experiments previously revealed several such candidates that bind in the $c r e b B$ promoter region (data not shown). Prominent among these were (1) CREB family protein CREBA, a leucine-zipper transcription factor (Smolik et al., 1992) and (2) Shn, a zinc finger

C2H2 transcription factor encoded by the shn gene (Marty et al., 2000) which also was identified

in a transposon mutagenesis screen for impairment of 1-day memory after 10xS as the umnitza mutant (Dubnau et al., 2003) (described above, see figure supplement 1).

Together, these findings implicated CREBA and Shn as candidate regulators of LTM formation through transcriptional activation of crebB. Interestingly, we inducibly overexpressed each in early $\alpha / \beta$ neurons and found enhanced 1-day memory after $1 \mathrm{x}$ or $3 \mathrm{xS}$ training with this manipulation of the $s h n^{+}$transgene but not $c r e b A^{+}$(Figure 10A; figure supplement 7A-B). We also observed strongly elevated CREBB protein expression in transgenic $s h n^{+}$flies, but not in transgenic $r u t^{+}$or $P k a^{a c t l}$ flies (figure supplement 8). Moreover, inducible RNAi knockdowns of shn but not crebA impaired 1-day memory after 10xS (Figure 10B; figure supplement 7C), and further impairment was not seen with systemic protein synthesis inhibition after CXM feeding (Figure 10B, right).

Memory after 10xS was fully rescued in shn knockdown flies by crebB co-expression (Figure 10C) and was enhanced relative to controls after 1x (Figure 10D). Taken together, these results show that

CREBB expression in early $\alpha / \beta$ neurons in response to spaced training is Shn-dependent.

\section{Discussion}


Our data suggest that MB neurons provide a compelling cellular gating mechanism for LTM

formation. A single training session is sufficient to increase early $\alpha / \beta$ neuronal excitability, the

output from which produces a downstream inhibitory effect on LTM formation. After spaced

training, cAMP signaling regulates neural excitability and/or Shn increases CREBB expression, the

net effects of which we suggest then represses further protein synthesis, thereby reducing early $\alpha / \beta$

output and relieving the inhibitory effect on LTM formation. Remarkably, our observations

emerged from a screen of enhancer trap memory mutants using Ricin ${ }^{\mathrm{CS}}$ protein synthesis inhibition

(figure supplement 1). 1-day memory after 10xS was impaired in nine lines, eight of which showed

expression in both MB \& DAL neurons. Curiously, another seven lines were not impaired in 1-day

memory after $10 \mathrm{xS}$ training - but they, too, showed enhancer expression patterns in MB \& DAL

neurons. We hypothesized that blocking protein synthesis in DAL neurons impaired LTM but doing

so in (some) MB neurons might actually enhance LTM, negating the inhibitory effects in DAL

neurons.

We tested this idea by maintaining Ricin ${ }^{\mathrm{CS}}$ expression in MB while blocking Ricin ${ }^{\mathrm{CS}}$ expression outside of MB using cry-Gal80 (Figure 1). Surprisingly, LTM now was enhanced in all seven of these enhancer trap lines (Figure 1). We then identified early $\alpha / \beta$ as the subset of MB neurons responsible for this enhancing effect (Figure 2). Inhibition protein synthesis in early $\alpha / \beta$ neurons during the first $6 \mathrm{~h}$, or blocking synaptic transmission from early $\alpha / \beta$ neurons during the first $8 \mathrm{~h}$ after training was sufficient to enhance LTM (Figure 3 and 4). Increasing excitability of early $\alpha / \beta$ neurons impaired LTM, but decreasing excitability again enhanced LTM (Figure 5). We next asked whether these neural excitability-dependent effects were also cAMP dependent. RNAi mediated knockdown of Rutabaga or PKA in early $\alpha / \beta$ impaired LTM, while overexpression of a $r^{+} t^{+}$or $P k a^{a c t l}$ transgene enhanced LTM (Figure 6 and 7). CREBB expression is suggest to be synergistically and post-transcriptionally regulated by protein kinases responding to cAMP signaling (15) and accordingly, our RNAi mediated knockdown of CREBB in early $\alpha / \beta$ impaired 
LTM, while overexpression of a $c r e b B$ transgene enhanced LTM (Figure 8). Finally, using a $c r e b B$

promoter driven Gal4 transgene, we show that CREBB transcription increases after 5xS or 10xS

spaced training but not after 1x training (Figure 9). Thus, spaced training-dependent expression of

CREBB repressor proteins in early $\alpha / \beta$ neurons blocks this inhibitory output from early

$\alpha / \beta$ neurons, thereby allowing LTM formation (downstream) to proceed.

An enhancing role associated with Shn-induced expression of CREBB repressor is a novel aspect of this LTM gating mechanism (Figure 10 and figure supplement 8). Previous reports have claimed

that chronic expression of a CREBB repressor or RNAi transgenes in all $\alpha / \beta$ neurons impaired 1-

day memory after spaced training (Yu et al., 2006; Lee et al., 2018). Chen et al., (2012) documented,

however, that these chronic disruptions of CREBB produced developmental abnormalities in MB

structure. In contrast, acute induced expression of active Ricin ${ }^{\mathrm{CS}}$ or CREBB repressor only in adult $\alpha / \beta$ neurons did not impair 1-day memory after spaced training (and did not produce structural defects). Using a different inducible system (MB247-Switch) to acutely expresses CREBB in $\gamma$ and $\alpha / \beta$ neurons, Hirano et al., (2016) showed a mild impairment of 1-day memory after spaced training. More interestingly, they used various molecular genetic tools to show that interactions among CREBB, CREB Binding Protein (CBP) and CREB Regulated Transcription Coactivator (CRTC) in MB clearly were involved in LTM formation or maintenance, respectively. Using the same inducible gene switch tool, Miyashita et al., (2018) showed a fascinating positive regulatory loop between Fos and CREBB in MB during LTM formation - but they did not show behavioral data pertaining to manipulation of CREBB per se- and they did not restrict their experiments to early $\alpha / \beta$ neurons.

A recent study that features cyclic AMP-response element $(C R E)$-driven transgenes is pertinent to this report. Zhang et al., (2015) expressed a CRE-luciferase transgene in different subpopulations of MB neurons and then monitored luciferase activity in live flies at various times after spaced training. Immediately after spaced training, they showed in some cases luciferase expression 
decreased (OK107 expressing in all MB neurons; c739 expressing in all $\alpha / \beta$ neurons; 1471

expressing in $\gamma$ neurons), in others expression increased ( $c 747$ and $c 772$ expressing variably in all

MB neurons) or in some no changes were detected (c320 expressing variably in $\gamma \alpha^{\prime} / \beta^{\prime}$ and $\alpha / \beta$

subpopulation, $17 d$ expressing primarily in late $\alpha / \beta$ and in early $\alpha / \beta$ neurons). Indeed, these authors

point out that, because CRE-luciferase was expressed in more than one subpopulation of MB

neurons, only net effects of CREB function could be quantified. Obviously, such a conclusion must

be drawn from any behavioral data collected after CREBB manipulations in multiple

subpopulations of MB neurons. Our study provides a dramatic example of this point. By restricting

our manipulation only to the early $\alpha / \beta$ neurons and only in adult stage animals, we show that acute overexpression or knockdown of CREBB enhances or impairs LTM formation, respectively (Figure 8) and that spaced training serves to increase the expression of CREBB in these neurons (Figure 9).

Of particular relevance to our future studies is the curious discovery that output from early $\alpha / \beta$ neurons specifically inhibits LTM formation. We find no evidence of inhibitory transmitter (i.e., GABA) synthesis or signaling in early $\alpha / \beta$ neurons, however, and others have suggested that memory-relevant MB output synapses are cholinergic (Barnstedt et al.,2016). Thus, we presume that inhibition of LTM lies somewhere downstream in the memory circuit. Furthermore, we note that ARM appears to involve $\alpha / \beta$ neurons (Lee et al.,2011; Knapek et al.,2011; Scholz-Kornehl and Schwärzel, 2016; Kotoula et al., 2017; Shyu et al., 2019) and to inhibit LTM formation (Isabel et al., 2004; Placais et al., 2012). Thus, a molecular link between ARM and LTM may reside in early $\alpha / \beta$ neurons.

More generally, our results underscore the need to study behavior-genetic relations in each of the seven MB neuronal subpopulations (Aso et al., 2014) separately before drawing firm conclusions about a role for $\mathrm{MB}$ in specific memory phases or in the dynamics of a larger memory circuit 330 involving neurons intrinsic and extrinsic to MB. With the more complex circuitries in vertebrate 
331 animal models, such deconstruction of memory formation into specific neuronal subtypes will be

332 even more critical and enlightening.

\section{Materials and Methods}

335 A collection of Drosophila P-Gal4 transposon insertions were previously selected in an enhancer trap mutagenesis screen for long-term memory phenotypes (Dubnau et al., 2003). The resultant

337 Gal4 expression patterns in seven of these mutants were leveraged to drive and temporally control 338 cold-sensitive Ricin ${ }^{\mathrm{CS}}$ activity to block protein synthesis in the identified neuron subsets. In addition, 339 we spatially restricted Ricin ${ }^{\mathrm{CS}}$ activity by inhibiting Gal4 with MB or DAL neuron-specific

transmission from these neurons with Gal4-targetted temperature-sensitive Dynamin ${ }^{\text {ts }}$ after training was used to test the implicated roles of these neurons in LTM consolidation (Dubnau et al., 2001;

McGuire et al., 2001). Spatial and temporal regulation of $\mathrm{K}^{+}$and $\mathrm{Na}^{+}$channel activity with transgene overexpression and RNAi knockdown within these neurons was used to assess the downstream impacts of signaling valence on LTM. Similarly, restricted expression of transgenes was used to examine the training-responsive effects on LTM. We evaluated training-responsive CREBB expression with confocal microscopy using a Gal4-targeted UV-sensitive KAEDE reporter system (Chen et al., 2012). In various experiments, flies were fed CXM to provide a systemic level

351 of protein synthesis inhibition. Detailed procedures for all methods are described in the 352 supplementary materials.

\section{Flies}


Fly stocks were maintained on standard corn meal/yeast/agar medium at $25 \pm 1{ }^{\circ} \mathrm{C}$ or $18 \pm 1^{\circ} \mathrm{C}$ and $70 \%$ relative humidity on a 12:12-h light:dark cycle. All genotypes and sources are listed in table supplement 2.

\section{Behaviour}

Olfactory associative learning was evaluated by training 6- to 7-day-old flies in a T-maze apparatus with a Pavlovian olfactory conditioning procedure (Tully and Quinn, 1985) as described previously (Chen et al., 2012; Pai et al., 2013; Wu et al., 2017). All experiments were conducted in the dark in an environment-controlled room at the required temperatures and $70 \%$ relative humidity. The odours used were 3-octanol (OCT) and 4-methylcyclohexanol (MCH). Each experiment consisted of two groups of approximately 100 flies, each of which was conditioned with one of the two odours. Flies were exposed sequentially to two odours that were carried through the training chamber in a current of air (odours were bubbled at $750 \mathrm{ml} / \mathrm{min}$ ). In a single training session, flies first were exposed for $60 \mathrm{~s}$ to the conditioned stimulus $\left(\mathrm{CS}^{+}\right)$, during which time they received the unconditioned stimulus (US), which consisted of 12 1.5-s pulses of $60 \mathrm{~V}$ dc electric shock presented at 5-s interpulse intervals. After the presentation of the CS+ condition, the chamber was flushed with fresh air for $45 \mathrm{~s}$. Then flies were exposed for $60 \mathrm{~s}$ to the unpaired $\mathrm{CS}^{-}$. To evaluate memory retention immediately after single-session training (acquisition), flies were gently tapped into an elevator-like compartment immediately after training. After $90 \mathrm{~s}$, the flies were transported to the choice point of a T-maze, in which they were exposed to two converging currents of air (one carrying $\mathrm{OCT}$, the other $\mathrm{MCH}$ ) from opposite arms of the maze. Flies were free to choose between and walk toward the $\mathrm{CS}^{+}$and $\mathrm{CS}^{-}$for $120 \mathrm{~s}$, at which time they were trapped inside the respective arms of the T-maze (by sliding the elevator out of the register), anesthetised, and counted. Flies that chose to avoid the $\mathrm{CS}^{+}$ran into the $\mathrm{T}$-maze arm containing the $\mathrm{CS}^{-}$, whereas flies that chose to avoid the $\mathrm{CS}^{-}$ran into the arm containing the $\mathrm{CS}^{+}$. For each experiment, a performance index $\left(\mathrm{PI}_{1,2}\right)=$ 
$380\left(\mathrm{~N}_{\mathrm{CS}}{ }_{-}-\mathrm{N}_{\mathrm{CS}+}\right) /\left(\mathrm{N}_{\mathrm{CS}}{ }_{-}+\mathrm{N}_{\mathrm{CS}+}\right)$ was calculated and averaged over these two complementary

381 experiments, with the final $\mathrm{PI}=\left(\mathrm{PI}_{1}+\mathrm{PI}_{2}\right) / 2$. Averaging of the two reciprocal scores eliminated

382 any potential biases originating from the machine, naïve odour preferences, or non-associative

383 changes in olfaction. For 24-h memory experiments, flies were subjected to single-session training,

384 training massed together without rest, or training spaced out with 15-min rest intervals. For these

training protocols, robotic trainers were used. All genotypes were trained and tested in parallel and

rotated among all of the robotic trainers to ensure a balanced experiment. The genetic backgrounds

of all fly strains were equilibrated to the "Canton" wild-type background by five or more

generations of backcrossing. In $t u b-G a l 80^{t s}$ experiments, flies raised at $18{ }^{\circ} \mathrm{C}$ were transferred to

$30{ }^{\circ} \mathrm{C}$ for at least five days before the experiments.

\section{Pharmacological treatment}

To block protein synthesis, flies were fed $35 \mathrm{mM}$ cycloheximide (Sigma) in $5 \%$ glucose 1 day

before training until immediately before the test (Tully et al., 1994).

crebB promoter construct

To engineer the $c r e b B$ promoter construct, polymerase chain reaction (PCR) was performed using genomic DNA from the wild-type Canton-S $w^{1118}$ (isolCJ) fly line as the template together with

the forward primer 5'GAAAAGTGCCACCTGCTGCATGTCTACCAACAGTTCGAG 3' and the reverse primer 5'CCGGATCTGCTAGCGGTTCCAGCTGCTGTCTGTATGAC 3'. A 11.6-kb att $P^{40}$-containing fly strains to obtain the transgenic fly lines.

PCR product was generated and inserted into the pBPGAL4.2Uw-2 vector, was digested with AatII and KpnI using In-Fusion ${ }^{\circledR}$ cloning system (Clontech). The promoter construct was injected into

\section{KAEDE measurement}


KAEDE is a photoconvertible green fluorescent protein, irreversibly changing its structure to a red

fluorescent protein upon ultraviolet irradiation (Ando et al., 2002). Taking advantage of circadian

transcription and protein synthesis in the lateral clock neurons, we previously validated de novo

KAEDE synthesis in per-Gal4>UAS-kaede flies, in which it faithfully reports the cyclic

transcriptions of the period gene. Feeding cycloheximide also suppressed green KAEDE synthesis, while not affecting the already-converted red KAEDE (Chen et al., 2012). To measure the amount

of newly synthesised KAEDE in MB neurons, we used procedures adapted from a previous study

(Chen et al., 2012). Briefly, pre-existing KAEDE proteins were photoconverted into red fluorescent

proteins by $365-395 \mathrm{~nm}$ UV irradiation generated from a 120-W mercury lamp. For behavioural testing, approximately 15-20 flies kept in a clear plastic syringe were directly exposed to UV light at a distance of $5 \mathrm{~cm}$ for $1 \mathrm{~h}$. Individual neurons expressing KAEDE were directly visualised through an open window in the fly's head capsule. Living samples were used because the signalto-noise ratio of green to red KAEDE is greatly reduced after chemical fixation. KAEDE neurons were located in less than $5 \mathrm{~s}$ by a fast pre-scanning of red KAEDE excited by a 561-nm laser, to avoid unnecessary fluorescence quenching of green KAEDE during repeated scanning. A single optical slice through the MB $\alpha$-lobe tip was imaged at a resolution of $1024 \times 1024$ pixels under a confocal microscope with a 40× C-Apochromat water-immersion objective lens (N.A. value 1.2, working distance $220 \mu \mathrm{m})$. All brain samples in the experiment were imaged with the same optical settings maximised for green and red KAEDE immediately before and after photoconversion, respectively. In all cases, both green KAEDE (excited by a 488-nm laser) and red KAEDE (excited by a 561-nm laser) were measured. By using the amount of red KAEDE as an internal standard to calibrate individual variation, we calculated the rate of increase in green KAEDE synthesis after photoconversion with the formula $(\Delta \mathrm{F})=\%\left(\mathrm{Ft}_{1}\right.$ - average $\left.\mathrm{Ft}_{0}\right) /$ average $\mathrm{Ft}_{0}$, where $\mathrm{Ft}_{1}$ and $\mathrm{Ft}_{0}$ are the ratios of the averaged intensities of green $(\mathrm{G})$ to red $(\mathrm{R}) \mathrm{KAEDE}\left(\mathrm{Gt}_{0} / \mathrm{Rt}_{0}\right)$ immediately after photoconversion ( $\left.\mathrm{t}_{0}\right)$ and at a later specific time point $\left(\mathrm{t}_{1}\right)$, respectively. 


\section{Spatiotemporal inhibition of protein synthesis}

432 Ricin ${ }^{\mathrm{CS}}$, a mutated Ricin A chain, inactivates eukaryotic ribosomes by hydrolytically cleaving the

$\mathrm{N}$-glycosidic bond (A4324) of the $28 \mathrm{~S}$ ribosomal RNA subunit at high temperatures $\left(30^{\circ} \mathrm{C}\right)$, but

not at low temperatures $\left(18^{\circ} \mathrm{C}\right)($ Endo et al., 1987; Endo and Tsurugi, 1987; Moffat et al., 1992;

Allen et al., 2002). We previously validated the spatiotemporal effect of Ricin ${ }^{\mathrm{CS}}$ inhibition in the

Drosophila brain using lateral clock neurons. We found that Ricin ${ }^{\mathrm{CS}}$ can effectively inhibit $\sim 80 \%$

of protein synthesis at a permissive temperature $\left(30^{\circ} \mathrm{C}\right)$, which is quickly reversed to normal levels

restoration of ribosomal synthesis once $\operatorname{Ricin}^{\mathrm{CS}}$ becomes inactive. While active $\mathrm{Ricin}^{\mathrm{CS}}$ is a potent cytotoxin for inhibiting protein synthesis, it tends not to be lethal, as Ricin ${ }^{\mathrm{CS}}$ eventually inhibits its own synthesis (Chen et al., 2012, Moffat et al., 1992; Allen et al., 2002). In the current experiments, two copies of Ricin ${ }^{\mathrm{CS}}$ was used to block protein synthesis. All flies were raised at $18^{\circ} \mathrm{C}$ to keep Ricin ${ }^{\mathrm{CS}}$ inactive. Before or after training at $18^{\circ} \mathrm{C}$, the Gal4>UAS-ricin ${ }^{C S} ; U A S$-ricin ${ }^{C S}$ flies were transferred to $30^{\circ} \mathrm{C}$ for $24 \mathrm{~h}$ to activate Ricin ${ }^{\mathrm{CS}}$, and then shifted back to $18^{\circ} \mathrm{C}$ for $1 \mathrm{~h}$ to inactivate Ricin $^{\mathrm{CS}}$ before the experiments. Temporal control of Ricin ${ }^{\mathrm{CS}}$ activation is indicated in the figures for the relevant experiments.

\section{Immunohistochemistry}

Brains were dissected in phosphate-buffered saline (PBS), fixed with a commercial microwave oven $(2,450 \mathrm{MHz}, 1100$ Watts $)$ in $4 \%$ paraformaldehyde on ice for $60 \mathrm{~s}$ three times, and then immersed in $4 \%$ paraformaldehyde with $0.25 \%$ Triton X-100 for $60 \mathrm{~s}$ three times. After being washed in PBS for $10 \mathrm{~min}$ at room temperature, brain samples were incubated in PBS containing $2 \%$ Triton X-100 (PBS-T) and 10\% normal goat serum, and then degassed in a vacuum chamber to expel tracheal air for four cycles (depressurizing to $-70 \mathrm{mmHg}$ and then holding for $10 \mathrm{~min}$ ). Next, 
brain samples were blocked and penetrated in PBS-T at $4{ }^{\circ} \mathrm{C}$ overnight, and then incubated in PBS-

T containing (1) 1:40 mouse 4F3 anti-DLG antibody (Developmental Studies Hybridoma Bank,

University of Iowa) to label Disc large proteins, and (2) 1:500 mouse anti-CREBB $\alpha 657$ antibody

(from Jerry Yin (Tubon et al., 2013)) at $4{ }^{\circ} \mathrm{C}$ for 1 day. Samples were subsequently washed in PBS-

$\mathrm{T}$ three times and incubated in PBS-T containing 1:200 biotinylated goat anti-mouse IgG

(Molecular Probes) as the secondary antibody at $25^{\circ} \mathrm{C}$ for 1 day. Brain samples were then washed

and incubated with 1:500 Alexa Fluor 635 streptavidin (Molecular Probes) at $25{ }^{\circ} \mathrm{C}$ for 1 day.

Finally, after extensive washing, immunolabeled brain samples were directly cleared for 5 min in

FocusClear, an aqueous solution that renders biological tissue transparent (Chiang et al., 2001),

and mounted between two cover slips separated by a spacer ring with a thickness of $\sim 200 \mu \mathrm{m}$.

Sample brains were imaged under a Zeiss LSM 780 or 880 confocal microscope with a 40× C-

Apochromat water-immersion objective lens (N.A. value 1.2, working distance $220 \mu \mathrm{m}$ ).

\section{Statistics}

All raw data were analysed parametrically with SigmaPlot 10.0 and SigmaStat 3.5 statistical software. All the data including the behaviour Performance Index $(\mathrm{PI})$ or KAEDE image $(\Delta \mathrm{F})$ were evaluated via unpaired $t$-test (two groups) or one-way analysis of variance (ANOVA) (> two groups). Data were evaluated with the Mann-Whitney Rank Sum Test in cases of unequal variances. Data in all figures are presented as the mean \pm SE. Experiments were replicated using multiple Gal4 drivers with equivalent expression patterns, and multiple effector genes and reagents that impact shared cellular functions.

\section{Acknowledgments}


We thank the Bloomington Drosophila stock center, Vienna Drosophila RNAi Center (VDRC) and Kyoto Drosophila Genomics Resource Centers (DGRC) for fly stocks. We also thank the Developmental Studies Hybridoma Bank for the antibodies.

Funding: This work was financially supported by

- The Brain Research Center under the Higher Education Sprout Project co-funded by the Ministry of Education and the Ministry of Science and Technology in Taiwan

- Yushan Scholar Program from the Ministry of Education in Taiwan

- $\quad$ Dart NeuroScience LLC in U.S.A.

\section{Author contributions:}

Conceived the project, analysed the data, and wrote the manuscript: C.C.C., J.S.D., T.T. and A.S.C.

Imaging experiments: H.W.L.

Behavioural experiments: C.C.C. and F.K.L.

Generated creb2-Gal4 transgenic flies: R.Y.J. and L.C.

Competing interests: All other authors declare they have no competing interests.

Data and materials availability: All data are available in the main text or the supplementary materials.

\section{References}

Allen, M.J., O'Kane, C.J., and Moffat, K.G. (2002). Cell ablation using wild-type and coldsensitive ricin-A chain in Drosophila embryonic mesoderm. Genesis 34, 132-134. 
Ando, R., Hama, H., Yamamoto-Hino, M., Mizuno, H., and Miyawaki, A. (2002). An optical

marker based on the UV-induced green-to-red photoconversion of a fluorescent protein. Proc Natl Acad Sci U S A 99, 12651-12656.

Aso, Y., Hattori, D., Yu, Y., Johnston, R.M., Iyer, N.A., Ngo, T.T., Dionne, H., Abbott, L.F.,

Axel, R., Tanimoto, H., et al. (2014). The neuronal architecture of the mushroom body provides a

logic for associative learning. Elife 3, e04577.

Baines, R.A. (2003). Postsynaptic protein kinase A reduces neuronal excitability in response to increased synaptic excitation in the Drosophila CNS. J Neurosci 23, 8664-8672.

Barnstedt, O., Owald, D., Felsenberg, J., Brain, R., Moszynski, J.P., Talbot, C.B., Perrat, P.N., and Waddell, S. (2016). Memory-Relevant Mushroom Body Output Synapses Are Cholinergic.

511 Neuron 89, 1237-1247.

Blum, A.L., Li, W., Cressy, M., and Dubnau, J. (2009). Short- and long-term memory in

Drosophila require cAMP signaling in distinct neuron types. Curr Biol 19, 1341-1350.

Bouzaiane, E., Trannoy, S., Scheunemann, L., Placais, P.Y., and Preat, T. (2015). Two

independent mushroom body output circuits retrieve the six discrete components of Drosophila aversive memory. Cell Rep 11, 1280-1292.

Chen, C.C., Wu, J.K., Lin, H.W., Pai, T.P., Fu, T.F., Wu, C.L., Tully, T., and Chiang, A.S. (2012). Visualizing long-term memory formation in two neurons of the Drosophila brain. Science $335,678-685$.

Chiang, A.S., Liu, Y.C., Chiu, S.L., Hu, S.H., Huang, C.Y., and Hsieh, C.H. (2001). Threedimensional mapping of brain neuropils in the cockroach, Diploptera punctata. J Comp Neurol $440,1-11$.

Cognigni, P., Felsenberg, J., and Waddell, S. (2018). Do the right thing: neural network mechanisms of memory formation, expression and update in Drosophila. Curr Opin Neurobiol $49,51-58$. 
Davis, G.W., DiAntonio, A., Petersen, S.A., and Goodman, C.S. (1998). Postsynaptic PKA

controls quantal size and reveals a retrograde signal that regulates presynaptic transmitter release

in Drosophila. Neuron 20, 305-315.

Davis, R.L. (2015). SnapShot: Olfactory Classical Conditioning of Drosophila. Cell 163, 524-524

$530 \quad \mathrm{e} 521$.

Dubnau, J., and Chiang, A.S. (2013). Systems memory consolidation in Drosophila. Curr Opin

532 Neurobiol 23, 84-91.

533 Dubnau, J., Chiang, A.S., Grady, L., Barditch, J., Gossweiler, S., McNeil, J., Smith, P., Buldoc,

F., Scott, R., Certa, U., et al. (2003). The staufen/pumilio pathway is involved in Drosophila longterm memory. Curr Biol 13, 286-296.

Dubnau, J., Grady, L., Kitamoto, T., and Tully, T. (2001). Disruption of neurotransmission in Drosophila mushroom body blocks retrieval but not acquisition of memory. Nature 411, 476-480.

Dudai, Y., Jan, Y.N., Byers, D., Quinn, W.G., and Benzer, S. (1976). dunce, a mutant of

Drosophila deficient in learning. Proc Natl Acad Sci U S A 73, 1684-1688.

Endo, Y., Mitsui, K., Motizuki, M., and Tsurugi, K. (1987). The mechanism of action of ricin and related toxic lectins on eukaryotic ribosomes. The site and the characteristics of the modification in $28 \mathrm{~S}$ ribosomal RNA caused by the toxins. J Biol Chem 262, 5908-5912.

Endo, Y., and Tsurugi, K. (1987). RNA N-glycosidase activity of ricin A-chain. Mechanism of action of the toxic lectin ricin on eukaryotic ribosomes. J Biol Chem 262, 8128-8130.

Fropf, R., Zhang, J., Tanenhaus, A.K., Fropf, W.J., Siefkes, E., and Yin, J.C. (2014). Time of day influences memory formation and dCREB2 proteins in Drosophila. Front Syst Neurosci 8, 43. Ge, X., Hannan, F., Xie, Z., Feng, C., Tully, T., Zhou, H., Xie, Z., and Zhong, Y. (2004). Notch signaling in Drosophila long-term memory formation. Proc Natl Acad Sci U S A 101, 1017210176. 
Hirano, Y., Ihara, K., Masuda, T., Yamamoto, T., Iwata, I., Takahashi, A., Awata, H., Nakamura,

N., Takakura, M., Suzuki, Y., et al. (2016). Shifting transcriptional machinery is required for

long-term memory maintenance and modification in Drosophila mushroom bodies. Nat Commun

$7,13471$.

Hodge, J.J., Choi, J.C., O'Kane, C.J., and Griffith, L.C. (2005). Shaw potassium channel genes in

Drosophila. J Neurobiol 63, 235-254.

Huang, C., Zheng, X., Zhao, H., Li, M., Wang, P., Xie, Z., Wang, L., and Zhong, Y. (2012). A

557 permissive role of mushroom body alpha/beta core neurons in long-term memory consolidation in

Drosophila. Curr Biol 22, 1981-1989.

559 Isabel, G., Pascual, A., and Preat, T. (2004). Exclusive consolidated memory phases in

Drosophila. Science 304, 1024-1027.

561 Ito, K., Awano, W., Suzuki, K., Hiromi, Y., and Yamamoto, D. (1997). The Drosophila

562 mushroom body is a quadruple structure of clonal units each of which contains a virtually

563 identical set of neurones and glial cells. Development 124, 761-771.

564 Joiner, W.J., Crocker, A., White, B.H., and Sehgal, A. (2006). Sleep in Drosophila is regulated by 565 adult mushroom bodies. Nature 441, 757-760.

566 Knapek, S., Sigrist, S., and Tanimoto, H. (2011). Bruchpilot, a synaptic active zone protein for 567 anesthesia-resistant memory. J Neurosci 31, 3453-3458.

568 Kotoula, V., Moressis, A., Semelidou, O., and Skoulakis, E.M.C. (2017). Drk-mediated signaling 569 to Rho kinase is required for anesthesia-resistant memory in Drosophila. Proc Natl Acad Sci U S A $114,10984-10989$.

571 Krashes, M.J., Keene, A.C., Leung, B., Armstrong, J.D., and Waddell, S. (2007). Sequential use 572 of mushroom body neuron subsets during Drosophila odor memory processing. Neuron 53, 103573 115. 
Lee, P.T., Lin, G., Lin, W.W., Diao, F., White, B.H., and Bellen, H.J. (2018). A kinase-dependent

feedforward loop affects CREBB stability and long term memory formation. Elife 7.

\section{6}

Lee, P.T., Lin, H.W., Chang, Y.H., Fu, T.F., Dubnau, J., Hirsh, J., Lee, T., and Chiang, A.S. (2011). Serotonin-mushroom body circuit modulating the formation of anesthesia-resistant memory in Drosophila. Proc Natl Acad Sci U S A 108, 13794-13799.

Lin, H.H., Lai, J.S., Chin, A.L., Chen, Y.C., and Chiang, A.S. (2007). A map of olfactory representation in the Drosophila mushroom body. Cell 128, 1205-1217.

Marty, T., Muller, B., Basler, K., and Affolter, M. (2000). Schnurri mediates Dpp-dependent repression of brinker transcription. Nat Cell Biol 2, 745-749.

McGuire, S.E., Le, P.T., and Davis, R.L. (2001). The role of Drosophila mushroom body signaling in olfactory memory. Science 293, 1330-1333.

McGuire, S.E., Le, P.T., Osborn, A.J., Matsumoto, K., and Davis, R.L. (2003). Spatiotemporal rescue of memory dysfunction in Drosophila. Science 302, 1765-1768.

Miyashita, T., Kikuchi, E., Horiuchi, J., and Saitoe, M. (2018). Long-Term Memory Engram Cells Are Established by c-Fos/CREB Transcriptional Cycling. Cell Rep 25, 2716-2728 e2713. Moffat, K.G., Gould, J.H., Smith, H.K., and O'Kane, C.J. (1992). Inducible cell ablation in Drosophila by cold-sensitive ricin A chain. Development 114, 681-687.

Pai, T.P., Chen, C.C., Lin, H.H., Chin, A.L., Lai, J.S., Lee, P.T., Tully, T., and Chiang, A.S. (2013). Drosophila ORB protein in two mushroom body output neurons is necessary for longterm memory formation. Proc Natl Acad Sci U S A 110, 7898-7903.

Pavlopoulos, E., Anezaki, M., and Skoulakis, E.M. (2008). Neuralized is expressed in the alpha/beta lobes of adult Drosophila mushroom bodies and facilitates olfactory long-term memory formation. Proc Natl Acad Sci U S A 105, 14674-14679.

Perisse, E., Burke, C., Huetteroth, W., and Waddell, S. (2013). Shocking revelations and saccharin sweetness in the study of Drosophila olfactory memory. Curr Biol 23, R752-763. 
Placais, P.Y., Trannoy, S., Isabel, G., Aso, Y., Siwanowicz, I., Belliart-Guerin, G., Vernier, P.,

Birman, S., Tanimoto, H., and Preat, T. (2012). Slow oscillations in two pairs of dopaminergic neurons gate long-term memory formation in Drosophila. Nat Neurosci 15, 592-599.

Presente, A., Boyles, R.S., Serway, C.N., de Belle, J.S., and Andres, A.J. (2004). Notch is required for long-term memory in Drosophila. Proc Natl Acad Sci U S A 101, 1764-1768.

Quinn, W.G., and Dudai, Y. (1976). Memory phases in Drosophila. Nature 262, 576-577.

Scheunemann, L., Jost, E., Richlitzki, A., Day, J.P., Sebastian, S., Thum, A.S., Efetova, M., Davies, S.A., and Schwarzel, M. (2012). Consolidated and labile odor memory are separately encoded within the Drosophila brain. J Neurosci 32, 17163-17171.

Scheunemann, L., Placais, P.Y., Dromard, Y., Schwarzel, M., and Preat, T. (2018). Dunce Phosphodiesterase Acts as a Checkpoint for Drosophila Long-Term Memory in a Pair of Serotonergic Neurons. Neuron 98, 350-365 e355.

Scholz-Kornehl, S., and Schwarzel, M. (2016). Circuit Analysis of a Drosophila Dopamine Type 2 Receptor That Supports Anesthesia-Resistant Memory. J Neurosci 36, 7936-7945.

Sejourne, J., Placais, P.Y., Aso, Y., Siwanowicz, I., Trannoy, S., Thoma, V., Tedjakumala, S.R., Rubin, G.M., Tchenio, P., Ito, K., et al. (2011). Mushroom body efferent neurons responsible for aversive olfactory memory retrieval in Drosophila. Nat Neurosci 14, 903-910.

Shyu, W.H., Lee, W.P., Chiang, M.H., Chang, C.C., Fu, T.F., Chiang, H.C., Wu, T., and Wu, C.L. (2019). Electrical synapses between mushroom body neurons are critical for consolidated memory retrieval in Drosophila. PLoS Genet 15, e1008153.

Smolik, S.M., Rose, R.E., and Goodman, R.H. (1992). A cyclic AMP-responsive element-binding transcriptional activator in Drosophila melanogaster, dCREB-A, is a member of the leucine zipper family. Mol Cell Biol 12, 4123-4131.

Stoleru, D., Peng, Y., Agosto, J., and Rosbash, M. (2004). Coupled oscillators control morning and evening locomotor behaviour of Drosophila. Nature 431, 862-868. 
Tanaka, N.K., Tanimoto, H., and Ito, K. (2008). Neuronal assemblies of the Drosophila

mushroom body. J Comp Neurol 508, 711-755.

\section{6}

Tonoki, A., and Davis, R.L. (2015). Aging impairs protein-synthesis-dependent long-term memory in Drosophila. J Neurosci 35, 1173-1180.

Tubon, T.C., Jr., Zhang, J., Friedman, E.L., Jin, H., Gonzales, E.D., Zhou, H., Drier, D., Gerstner, J.R., Paulson, E.A., Fropf, R., et al. (2013). dCREB2-mediated enhancement of memory formation. J Neurosci 33, 7475-7487.

Tully, T. (1996). Discovery of genes involved with learning and memory: an experimental synthesis of Hirschian and Benzerian perspectives. Proc Natl Acad Sci U S A 93, 13460-13467. Tully, T., Boynton, S., Brandes, C., Dura, J.M., Mihalek, R., Preat, T., and Villella, A. (1990). Genetic dissection of memory formation in Drosophila melanogaster. Cold Spring Harb Symp Quant Biol 55, 203-211.

Tully, T., Preat, T., Boynton, S.C., and Del Vecchio, M. (1994). Genetic dissection of consolidated memory in Drosophila. Cell 79, 35-47.

Tully, T., and Quinn, W.G. (1985). Classical conditioning and retention in normal and mutant Drosophila melanogaster. J Comp Physiol A 157, 263-277.

Venken, K.J., Simpson, J.H., and Bellen, H.J. (2011). Genetic manipulation of genes and cells in the nervous system of the fruit fly. Neuron 72, 202-230.

Wu, C.L., Shih, M.F., Lee, P.T., and Chiang, A.S. (2013). An octopamine-mushroom body circuit modulates the formation of anesthesia-resistant memory in Drosophila. Curr Biol 23, 2346-2354.

Wu, C.L., Xia, S., Fu, T.F., Wang, H., Chen, Y.H., Leong, D., Chiang, A.S., and Tully, T. (2007). Specific requirement of NMDA receptors for long-term memory consolidation in Drosophila ellipsoid body. Nat Neurosci 10, 1578-1586. 
Wu, J.K., Tai, C.Y., Feng, K.L., Chen, S.L., Chen, C.C., and Chiang, A.S. (2017). Long-term

memory requires sequential protein synthesis in three subsets of mushroom body output neurons in Drosophila. Sci Rep 7, 7112.

Yang, C.H., Shih, M.F., Chang, C.C., Chiang, M.H., Shih, H.W., Tsai, Y.L., Chiang, A.S., Fu,

T.F., and Wu, C.L. (2016). Additive Expression of Consolidated Memory through Drosophila

Mushroom Body Subsets. PLoS Genet 12, e1006061.

Yin, J.C., Del Vecchio, M., Zhou, H., and Tully, T. (1995a). CREB as a memory modulator:

induced expression of a dCREB2 activator isoform enhances long-term memory in Drosophila.

Yin, J.C., Wallach, J.S., Del Vecchio, M., Wilder, E.L., Zhou, H., Quinn, W.G., and Tully, T.

(1994). Induction of a dominant negative CREB transgene specifically blocks long-term memory in Drosophila. Cell 79, 49-58.

Yin, J.C., Wallach, J.S., Wilder, E.L., Klingensmith, J., Dang, D., Perrimon, N., Zhou, H., Tully,

T., and Quinn, W.G. (1995b). A Drosophila CREB/CREM homolog encodes multiple isoforms,

including a cyclic AMP-dependent protein kinase-responsive transcriptional activator and antagonist. Mol Cell Biol 15, 5123-5130.

Yu, D., Akalal, D.B., and Davis, R.L. (2006). Drosophila alpha/beta mushroom body neurons

664 form a branch-specific, long-term cellular memory trace after spaced olfactory conditioning.

665 Neuron 52, 845-855.

666 Zhang, J., Tanenhaus, A.K., Davis, J.C., Hanlon, B.M., and Yin, J.C. (2015). Spatio-temporal in 667 vivo recording of dCREB2 dynamics in Drosophila long-term memory processing. Neurobiol 668 Learn Mem 118, 80-88.

669 Zhang, S.X., Rogulja, D., and Crickmore, M.A. (2019). Recurrent Circuitry Sustains Drosophila 670 Courtship Drive While Priming Itself for Satiety. Curr Biol 29, 3216-3228 e3219. 
671 Zhu, S., Chiang, A.S., and Lee, T. (2003). Development of the Drosophila mushroom bodies:

672 elaboration, remodeling and spatial organization of dendrites in the calyx. Development 130,

$673 \quad 2603-2610$.

674

675

676

677

678

679

680

681

682

\section{Figures}

A
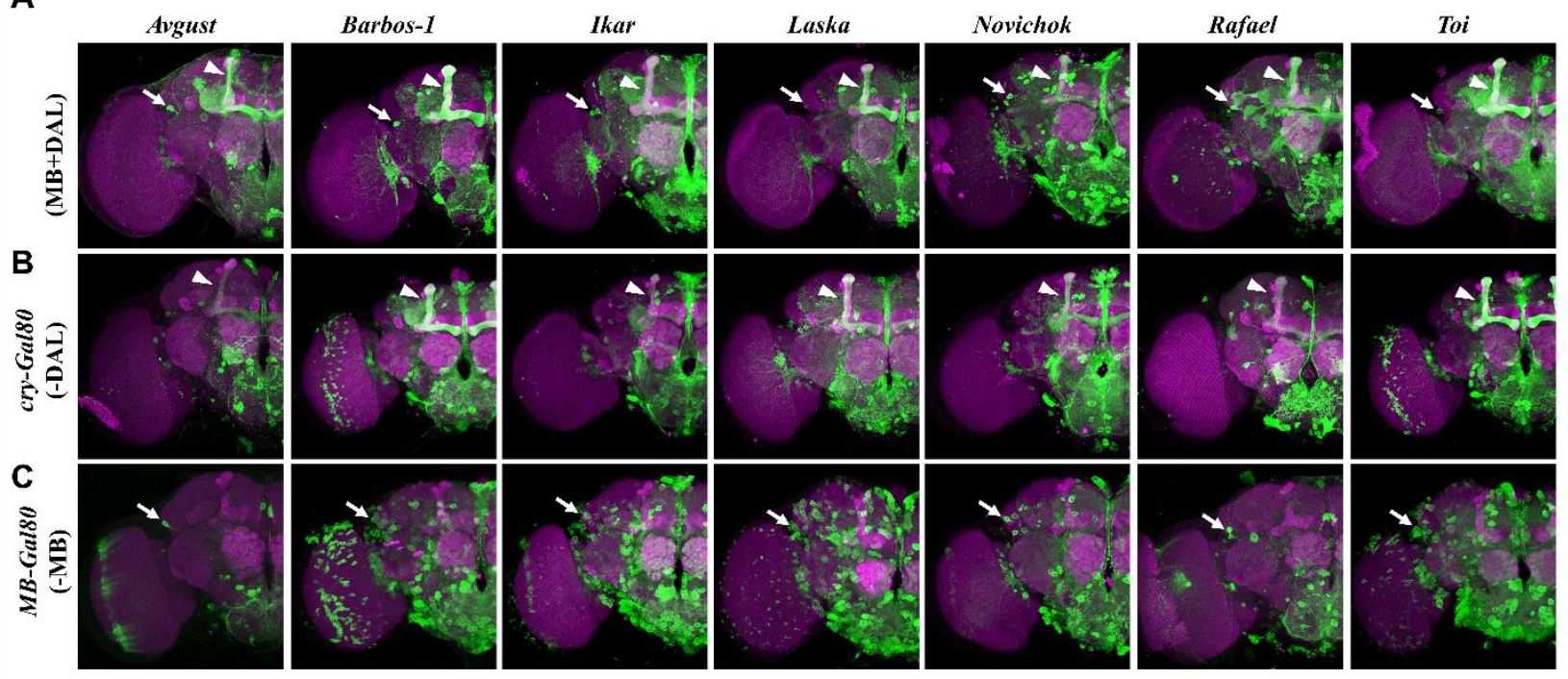

D

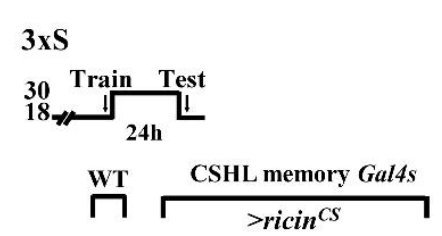

E

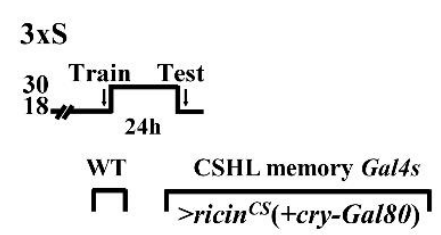

$\mathbf{F}$

$3 \mathrm{xS}$
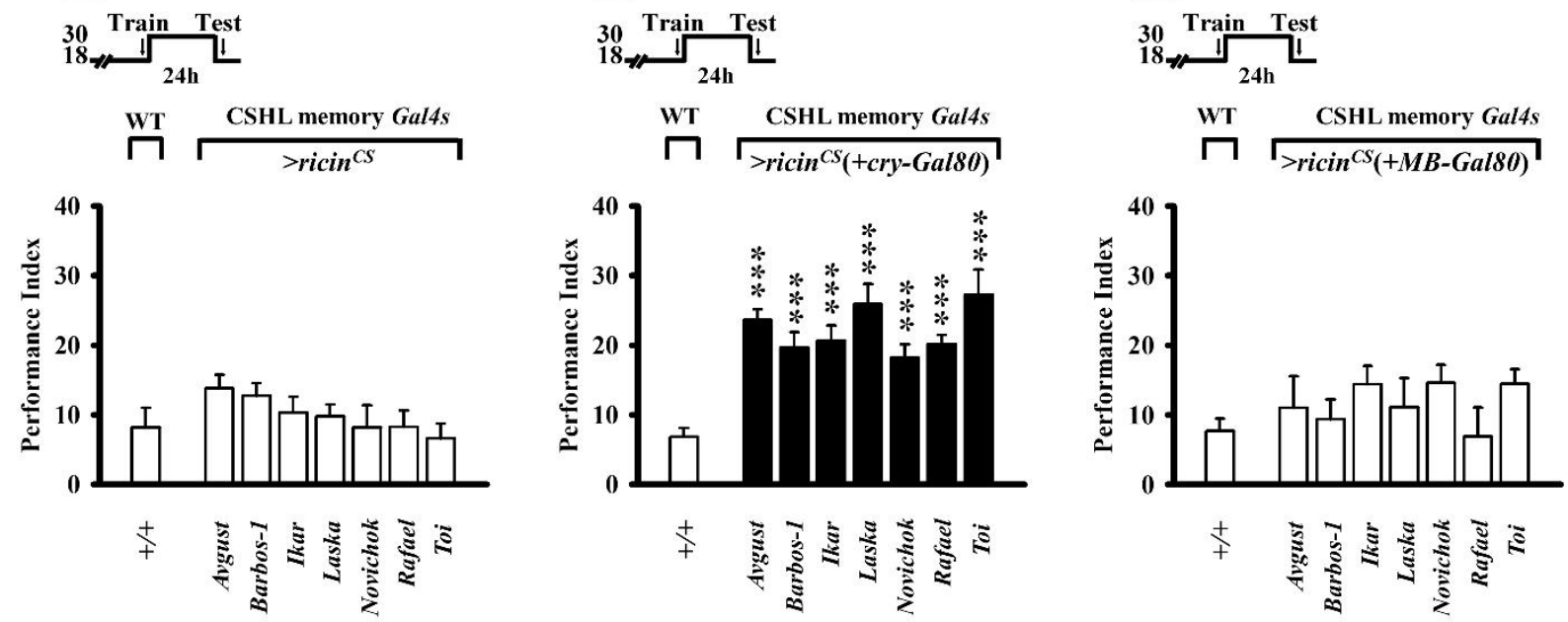

Figure 1 
bioRxiv preprint doi: https://doi.org/10.1101/2021.06.10.447902; this version posted June 10, 2021. The copyright holder for this preprint (which was not certified by peer review) is the author/funder, who has granted bioRxiv a license to display the preprint in perpetuity. It is made available under aCC-BY 4.0 International license.

A $\quad 3 \mathrm{xS}$

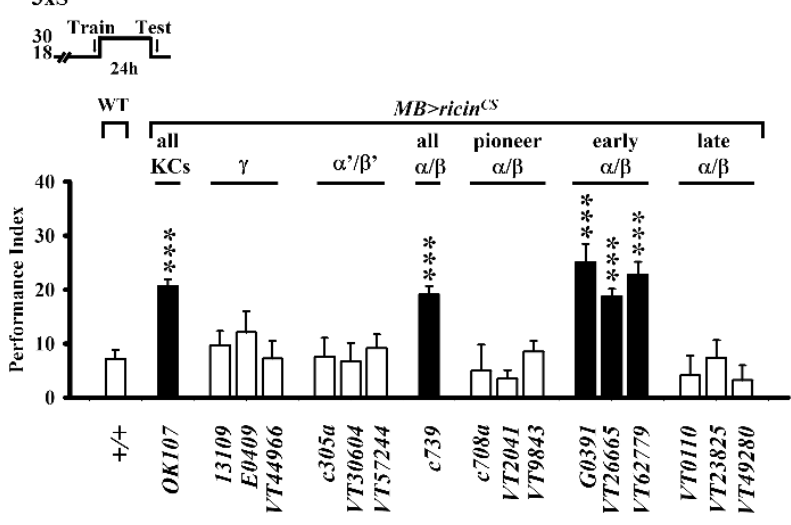

B

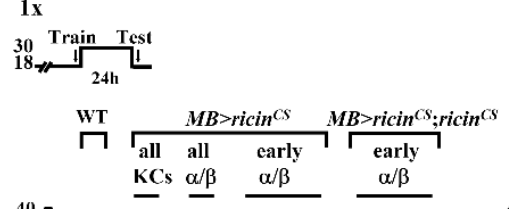

$1 \mathbf{x}$

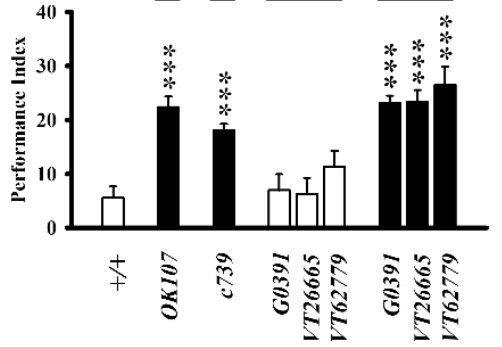

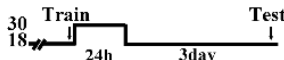

WT $M B>$ ricin $^{C S} M B>$ ricin $^{C S} ;$ ricin $^{C S}$

$\sqcap \Gamma_{\text {all all }} \Gamma_{\text {early }}$ KCs $\alpha / \beta \quad \alpha / \beta$

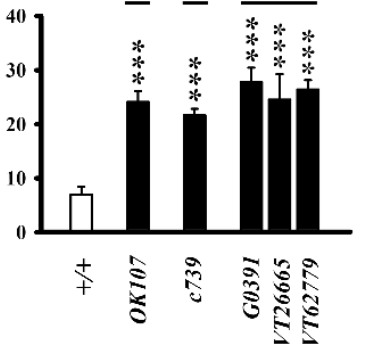

$3 \mathrm{xS}$

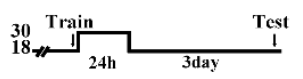

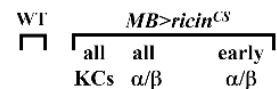

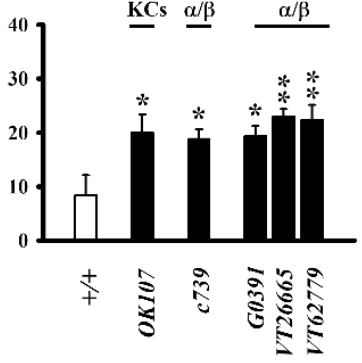

C

$1 \mathrm{x}$

${ }_{18}^{30} \underset{\text { Train }}{1} \frac{1}{14 \mathrm{~h}}$

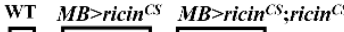

$\sqcap$ all all

$\underline{\mathrm{KCs}} \underline{\alpha / \beta} \underline{\alpha / \beta}$

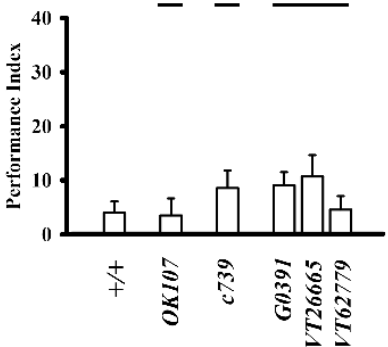

Figure 2 
bioRxiv preprint doi: https://doi.org/10.1101/2021.06.10.447902; this version posted June 10, 2021. The copyright holder for this preprint (which was not certified by peer review) is the author/funder, who has granted bioRxiv a license to display the preprint in perpetuity. It is made available under aCC-BY 4.0 International license.

A

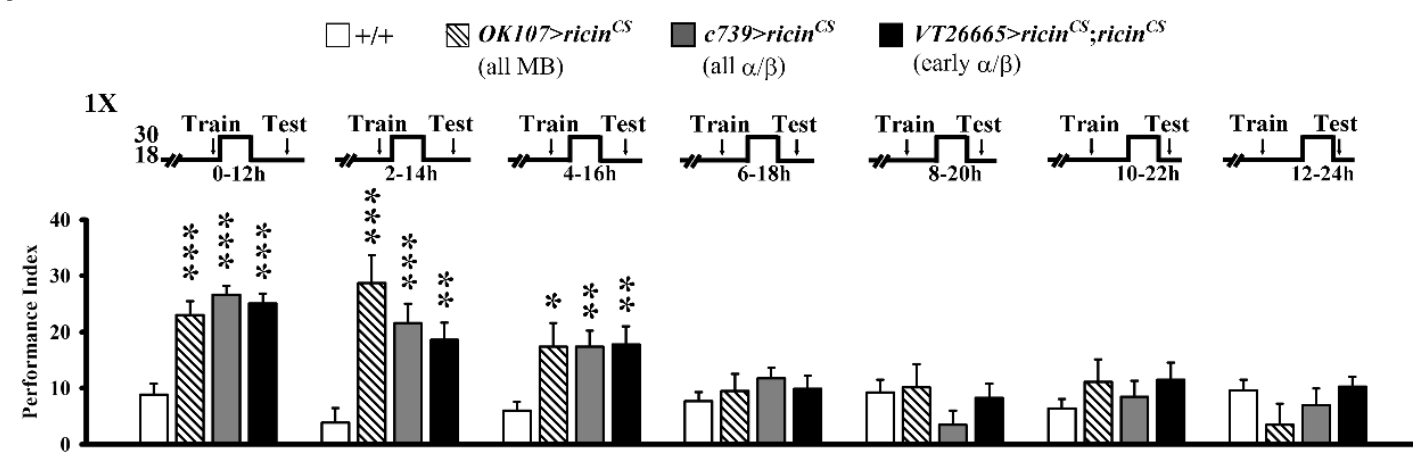

B

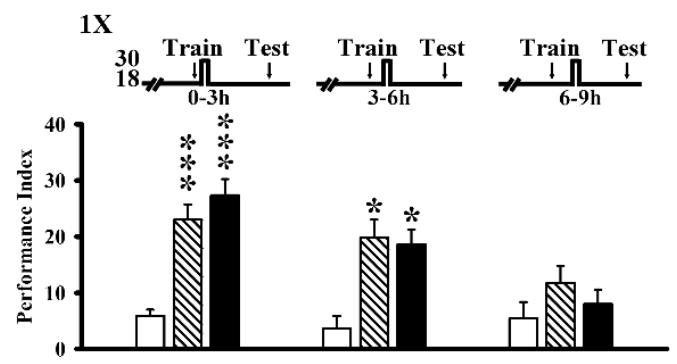

Figure 3 
bioRxiv preprint doi: https://doi.org/10.1101/2021.06.10.447902; this version posted June 10, 2021. The copyright holder for this preprint (which was not certified by peer review) is the author/funder, who has granted bioRxiv a license to display the preprint in perpetuity. It is made available under aCC-BY 4.0 International license.

A

$\square s h i^{t s /+} \quad \square V T 26665 /$ shits $^{t s}$

$3 \mathrm{xS}$

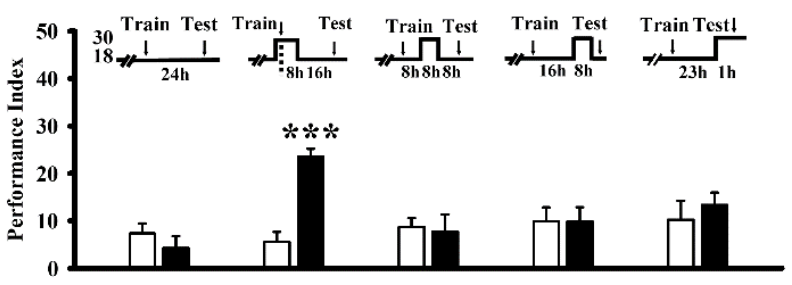

B

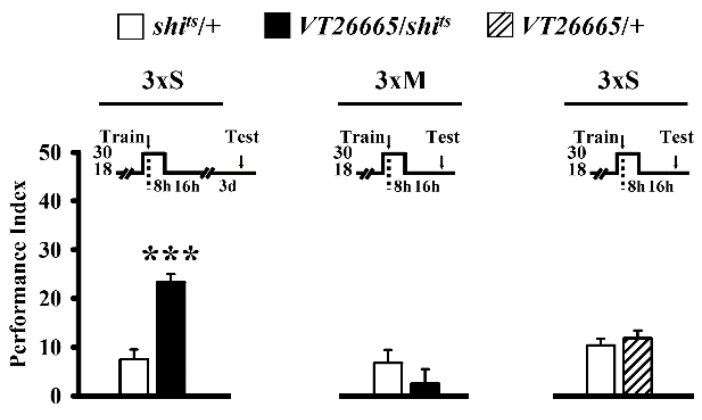

C

$\square s h i^{i s /+} \square G 0391 / s^{i t s} \quad \square V T 62779 / s^{s h} i^{* s}$
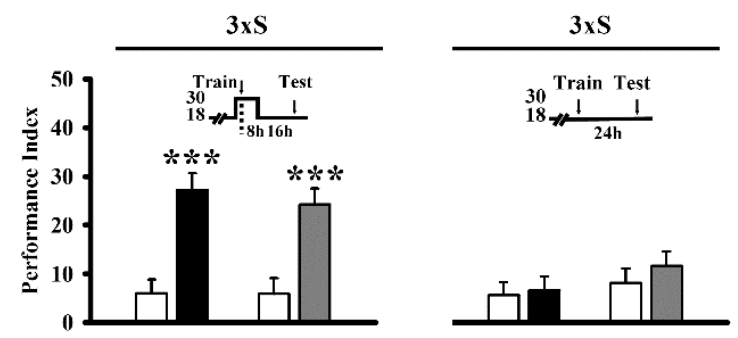

Figure 4 
bioRxiv preprint doi: https://doi.org/10.1101/2021.06.10.447902; this version posted June 10, 2021. The copyright holder for this preprint (which was not certified by peer review) is the author/funder, who has granted bioRxiv a license to display the preprint in perpetuity. It is made available under aCC-BY 4.0 International license.
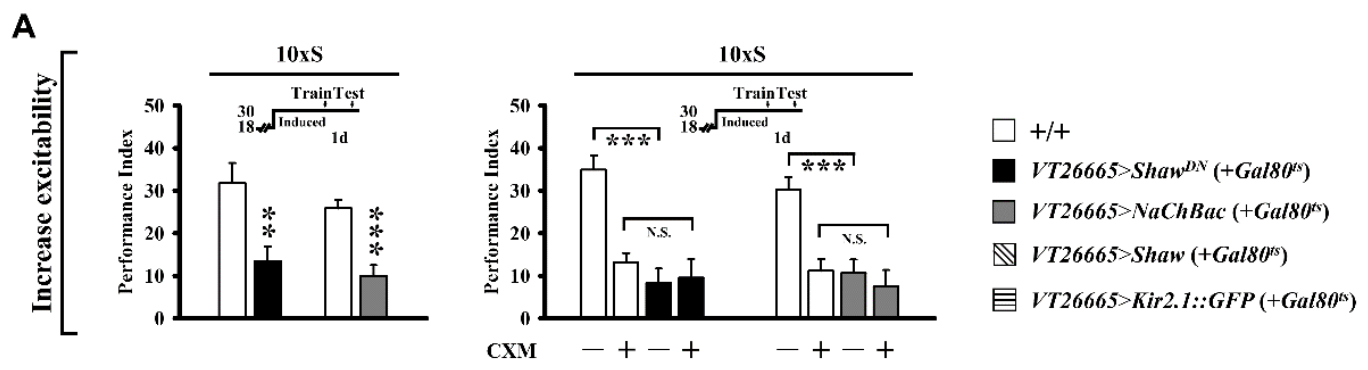

B
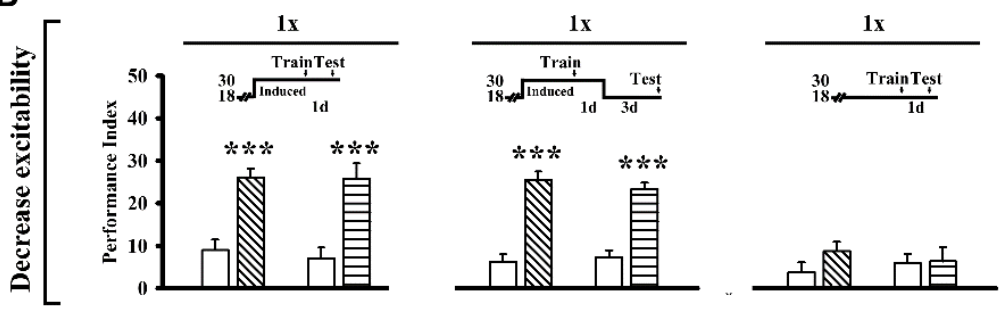

C

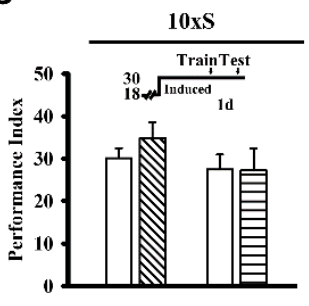

Figure 5 
bioRxiv preprint doi: https://doi.org/10.1101/2021.06.10.447902; this version posted June 10, 2021. The copyright holder for this preprint (which was not certified by peer review) is the author/funder, who has granted bioRxiv a license to display the preprint in perpetuity. It is made available under aCC-BY 4.0 International license.

A

$\square+/+\square V T 26665 /$ rut $^{+}\left(+G a l 80^{t s}\right) \quad \mathbb{V} V T 26665 /$ rut $^{R N A i(101759)}\left(+G a l 80^{t s}\right)$

$\square V T 26665 /$ rut $^{\text {RNAi (27035) }}\left(+\right.$ Gal80 $\left.^{t s}\right)$
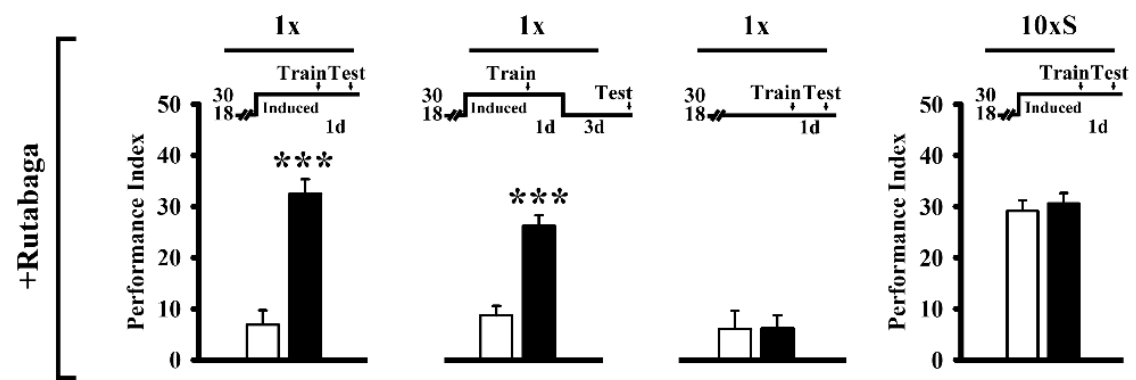

B
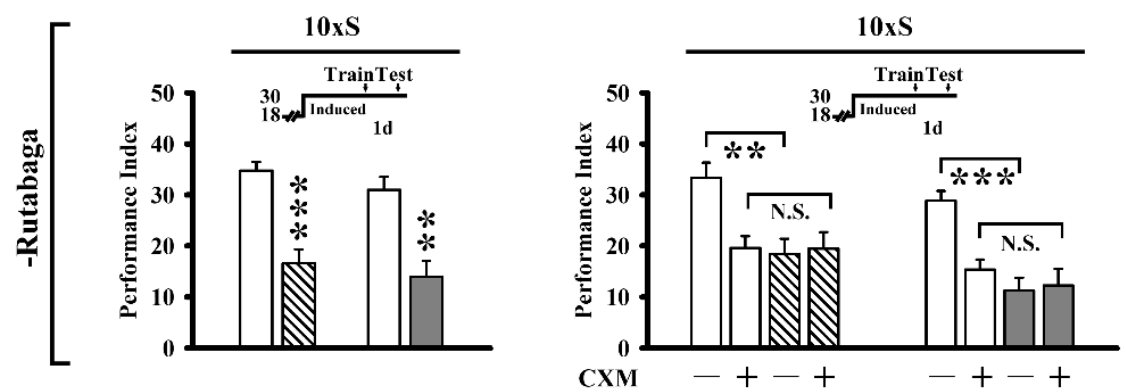

$694 \quad$ Figure 6 
bioRxiv preprint doi: https://doi.org/10.1101/2021.06.10.447902; this version posted June 10, 2021. The copyright holder for this preprint (which was not certified by peer review) is the author/funder, who has granted bioRxiv a license to display the preprint in perpetuity. It is made available under aCC-BY 4.0 International license.

A

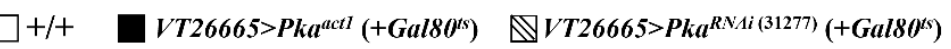

$\square V T 26665>P k a^{R N A i(101524)}\left(+G a l 80^{t s}\right)$
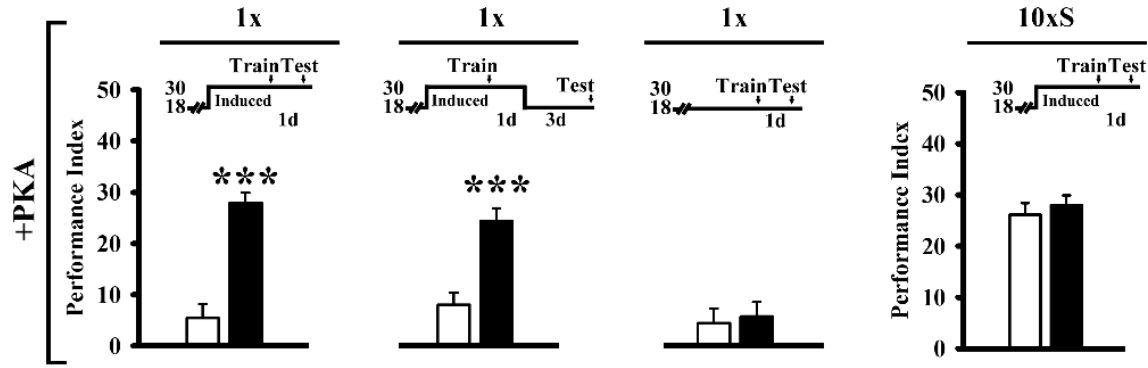

B
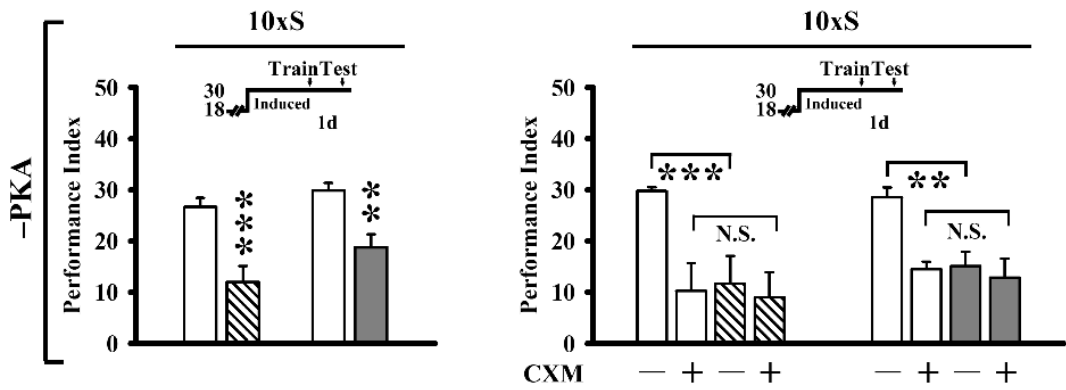

Figure 7 
bioRxiv preprint doi: https://doi.org/10.1101/2021.06.10.447902; this version posted June 10, 2021. The copyright holder for this preprint (which was not certified by peer review) is the author/funder, who has granted bioRxiv a license to display the preprint in perpetuity. It is made available under aCC-BY 4.0 International license.

$\square+/+\square V T 26665>\operatorname{crebB}\left(+G a l 80^{* s}\right)$

$\mathbb{Q} V T 26665>$ crebB $^{\text {RNAi }(101512)}\left(+G a l 80^{t s}\right)$

$V T 26665>$ crebB $^{\text {RNAi (29332) }}\left(+\right.$ Gal80 $\left.^{t s}\right)$

A
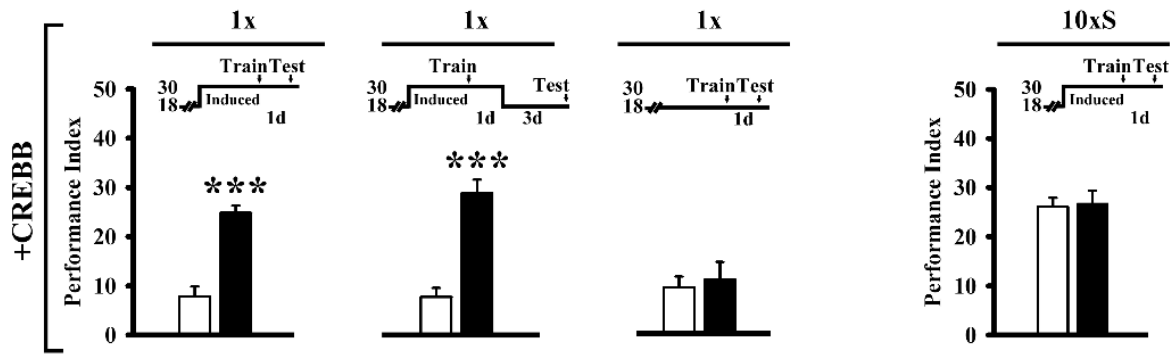

B
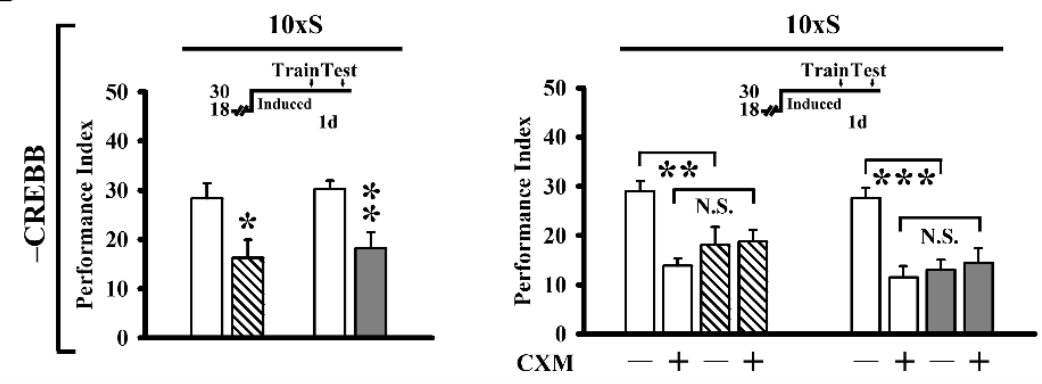

Figure 8 

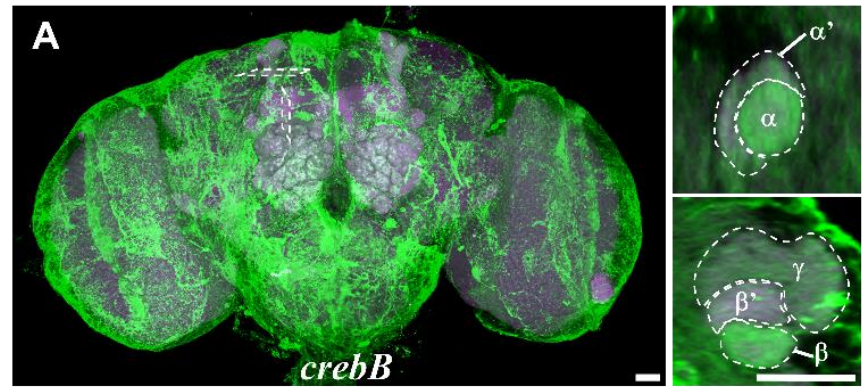

B

crebB-Gal4>UAS-kaede

699

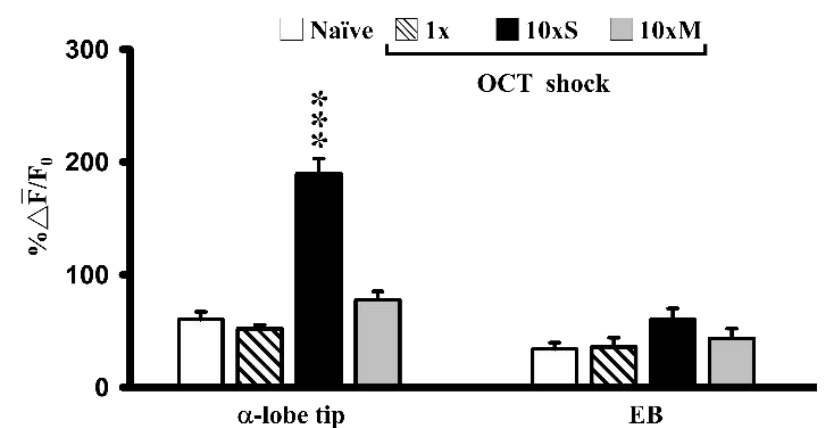

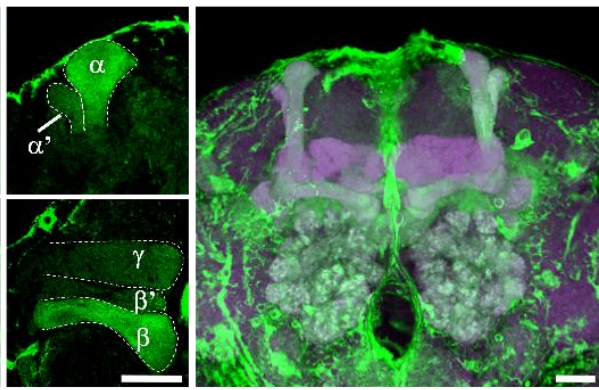

C

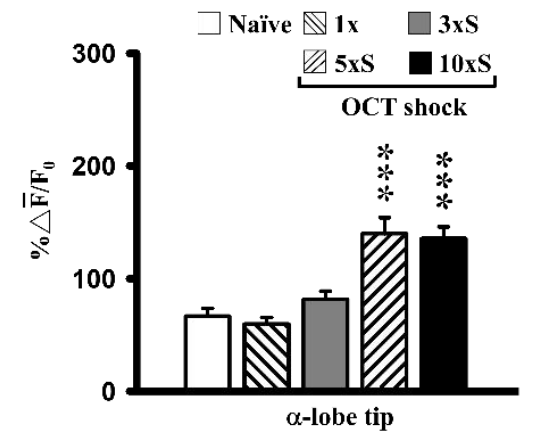

Figure 9 
bioRxiv preprint doi: https://doi.org/10.1101/2021.06.10.447902; this version posted June 10, 2021. The copyright holder for this preprint (which was not certified by peer review) is the author/funder, who has granted bioRxiv a license to display the preprint in perpetuity. It is made available under aCC-BY 4.0 International license.

A

$\square+/+\square V T 26665>\operatorname{shn}^{+(403 ; 401)}\left(+G a l 80^{t s}\right) \quad \mathbb{V} V 26665>\operatorname{shn}^{\text {RNAi (105643) }}\left(+\right.$ Gal80 $\left.^{\text {ts }}\right)$

目VT26665 $>\operatorname{shn} n^{R N A i(105643)}+\operatorname{crebB}\left(+G a l 80^{t s}\right) \quad \square V T 26665>\operatorname{sh} n^{R N A i(3226)}\left(+G a l 80^{t s}\right)$
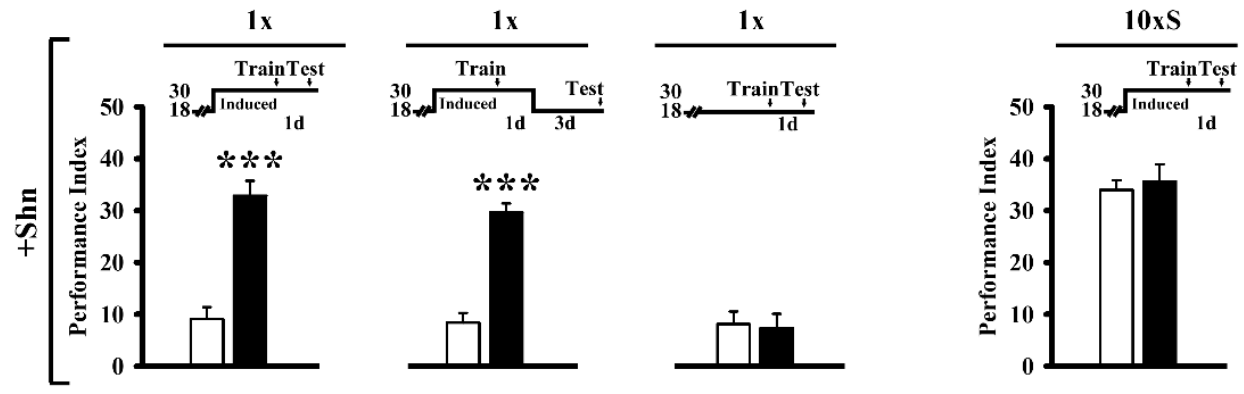

B
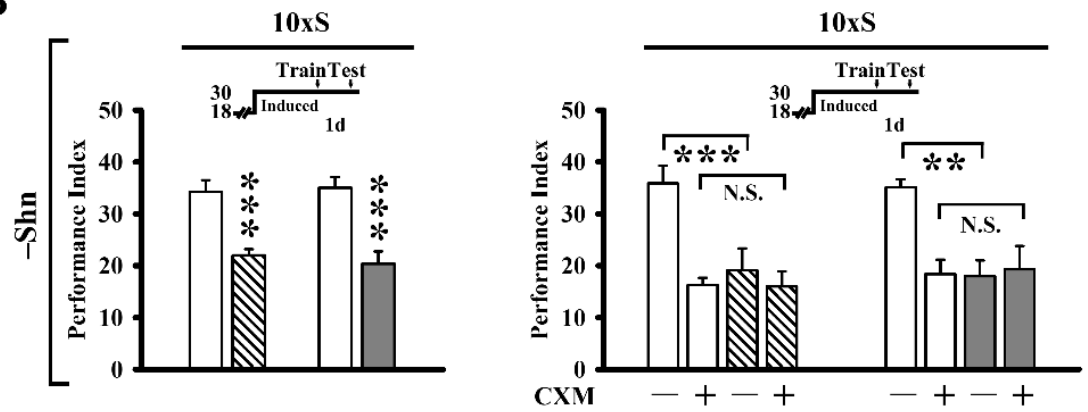

C

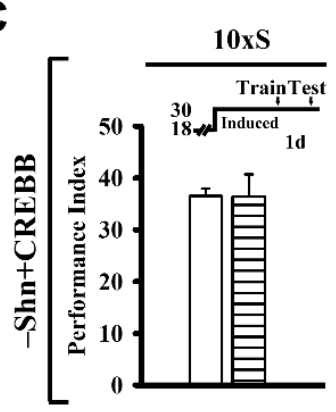

D

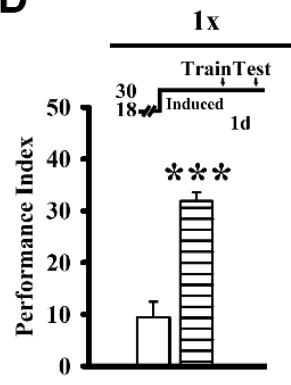

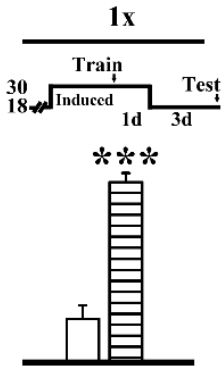

稙

\section{Figure 10}


Figure Legends

Figure 1. CSHL memory Gal4 patterns in which protein synthesis inhibition has no net

effect on LTM formation. (A) Full expression patterns that include MB and DAL neurons (top).

(B) Expression restricted from DAL neurons by cry-Gal80 inhibition of Gal4 (center). (C)

Expression restricted from MB neurons by $M B$-Gal80 inhibition of Gal4 (bottom). DAL (arrow)

formation. Effects of memory circuit Gal4-targeted Ricin ${ }^{\mathrm{CS}}$ on 1-day memory after three spaced training cycles $(3 \mathrm{xS})$, compared with wild-type $(+/+)$ controls. Cold-sensitive Ricin ${ }^{\mathrm{CS}}$ blocks protein synthesis at the permissive temperature $\left(30^{\circ} \mathrm{C}\right)$ between training and testing. (D) Protein synthesis inhibition in all Gal4-expressing elements of the memory circuit has no net effect on

(where cry-Gal80 inhibits Gal4), enhances 1-day memory in all seven Gal4 genotypes. (F) By

contrast, Ricin ${ }^{\mathrm{CS}}$ expression and blocking of protein synthesis in DAL but not in MB neurons (where $M B-G a l 80$ inhibits Gal4) has no effect on LTM. In all figures, temperature control schedules are indicated (top). Memory performance indices are calculated as the normalised percent avoidance of shock-paired odour. Bars represent mean $\pm \mathrm{SE}, n=8 /$ bar unless stated otherwise. *, $P<0.05$; **, $P<0.01$, ***, $P<0.001$. All genotypes are listed in table supplement 2.

Figure 2. Protein synthesis inhibition in early $\alpha / \beta$ MB neurons enhances LTM formation. Effects of MB Gal4-targeted Ricin ${ }^{\mathrm{CS}}$ on memory after sub-threshold training compared with wildtype controls (see MB Gal4 expression patterns in figure supplement 2A) (A) Protein synthesis inhibition in MB Gal4 patterns that include early $\alpha / \beta$ neurons enhance 1-day (left) and 4-day (right) memory after $3 \mathrm{xS}$ training. (B) Two copies of Ricin ${ }^{\mathrm{CS}}$ expressed in early $\alpha / \beta$ neurons are necessary to enhance 1-day (left) and 4-day (right) memory after 1x training, whereas only one 
copy of Ricin ${ }^{\mathrm{CS}}$ is insufficient. (C) Expression of inactive Ricin ${ }^{\mathrm{CS}}$ in $\alpha / \beta$ neurons at the restrictive temperature $\left(18^{\circ} \mathrm{C}\right)$ has no effect on memory after $1 \mathrm{x}$ training.

\section{Figure 3. Protein synthesis in early $\alpha / \beta$ neurons after subthreshold training antagonizes}

LTM formation. Blocking protein synthesis in all MB (OK107), all $\alpha / \beta$ (c739), and early $\alpha / \beta$ (VT26665) neurons 0-6 h after 1x training enhances 1-day memory compared with wild-type $(+/+)$ controls (related to Figure 2; also compare with Figure 4A). (A) Memory enhancement is significant in all groups with Ricin ${ }^{\mathrm{CS}}$ activity 0-12 h, 2-14 h and 4-16 h after training but not for later time windows. (B) Memory enhancement is significant in all groups with Ricin $^{\mathrm{CS}}$ activity 0$3 \mathrm{~h}$ and 3-6 h but not 6-9 h after training.

Figure 4. Blocking early $\alpha / \beta$ neuron signaling enhances LTM formation. Effects of early $\alpha / \beta$ Gal4-targeted Dynamin ${ }^{\text {ts }}\left(\operatorname{shi}^{\text {ts }}\right)$ on 1-day memory after $3 \mathrm{xS}$ training. (A) Blocking signaling in the first 8-h after training enhances 1-day memory, whereas blocking signaling during subsequent 8-h windows has no effect, compared with the unexpressed $s h t^{t s} /+$ control (also see figure supplement 4). (B) Similarly, blocking signaling in the first 8-h after 3xS training enhances 4-day memory (left), but not after 3xM training (center) or after 3xS training of the Gal4 driver or $s h i^{\text {ts }}$ transgene alone (right). (C) Blocking early $\alpha / \beta$ signaling using two additional Gal4 patterns confirms this inhibitory effect and enhancement of 1-day memory (left). Memory is unaffected in flies held at the permissive temperature $\left(18^{\circ} \mathrm{C}\right)$ after $3 \times \mathrm{S}$ training (right).

\section{Figure 5. Neural membrane excitability in early $\alpha / \beta$ neurons bi-directionally regulates LTM}

formation. $\mathrm{MB}$ early $\alpha / \beta$ Gal4-targeted expression of $\mathrm{K}^{+}$and $\mathrm{Na}^{+}$channel proteins is induced at the restrictive temperature for the $t u b-G a l 80^{t s}$ inhibitor $\left(30^{\circ} \mathrm{C}\right)$ from five days before training until testing. (A) Shaw $w^{D N}$ and $N a C h B a c$ overexpression increase neural activity and impair 1-day memory after 10xS training (left). The same LTM is similarly blocked by systemic protein synthesis inhibition induced by CXM feeding (right) (also see figure supplement 5). (B) In 
contrast, Shaw and Kir2.1::GFP overexpression decrease neural activity and enhance1-day memory after only $1 \mathrm{x}$ training (left), which endures for at least 4 days (center). Memory is unaffected in these flies held at the permissive temperature for tub-Gal80 ${ }^{t s}\left(18^{\circ} \mathrm{C}\right)$ after $1 \mathrm{x}$ training (right). (C) Decreasing neural activity as in (B) does not affect 1-day memory after 10xS training.

\section{Figure 6. Modulation of Rutabaga (AC) in early $\alpha / \beta$ neurons bi-directionally regulates LTM}

formation. (A) Overexpressing $\mathrm{AC}$ in early $\alpha / \beta$ neurons enhances 1 -day memory after only $1 \mathrm{x}$ training (left) and lasts at least four days (left center). Memory is unaffected in these flies held at the permissive temperature for $t u b-G a l 80^{t s}\left(18{ }^{\circ} \mathrm{C}\right)$ after $1 \mathrm{x}$ training (right center). One-day memory is unaffected in these flies held at $30{ }^{\circ} \mathrm{C}$ after $10 \mathrm{xS}$ training (right). Gal4-targeted rut ${ }^{+}$ overexpression is induced at the restrictive temperature for $t u b-G a l 80^{t s}\left(30^{\circ} \mathrm{C}\right)$ from five days prior to training until testing. (B) By contrast, adult-stage specific RNAi down-regulation of AC in early $\alpha / \beta$ neurons (two independent RNAi lines) impairs 1-day memory after 10xS training (left) (also see figure supplement 6). The same LTM is similarly blocked by systemic protein synthesis inhibition induced by cycloheximide (CXM) feeding (right).

\section{Figure 7. Modulation of PKA in early $\alpha / \beta$ neurons bi-directionally regulates LTM}

formation. (A) Overexpressing constitutively active PKA ${ }^{\text {act } 1}$ in early $\alpha / \beta$ neurons enhances 1 -day memory after only $1 \mathrm{x}$ training (left) and lasts at least four days (left center). Memory is unaffected in these flies held at the permissive temperature for $t u b-G a l 80^{t s}\left(18{ }^{\circ} \mathrm{C}\right)$ after $1 \mathrm{x}$ training (right center). One-day memory is unaffected in these flies held at $30^{\circ} \mathrm{C}$ after $10 \mathrm{xS}$ training (right). Gal4-targeted $\mathrm{PKA}^{\text {actl }}$ overexpression is induced at the restrictive temperature for $t u b$-Gal80 ${ }^{t s}$ (30 ${ }^{\circ} \mathrm{C}$ ) from five days prior to training until testing. (B) By contrast, adult-stage specific RNAi down-regulation of PKA in early $\alpha / \beta$ neurons (two independent RNAi lines) impairs 1-day memory after 10xS training (left) (also see figure supplement 6). The same LTM is similarly 
blocked by systemic protein synthesis inhibition induced by cycloheximide (CXM) feeding (right).

\section{Figure 8. Modulation of CREBB protein in early $\alpha / \beta$ neurons bi-directionally regulates}

LTM formation. (A) Overexpressing CREBB proteins in early $\alpha / \beta$ neurons enhances 1 -day memory after only $1 \mathrm{x}$ training (left) and lasts at least four days (center). Gal4-targeted crebB overexpression is induced at the restrictive temperature for $t u b-G a l 80^{t s}\left(30^{\circ} \mathrm{C}\right)$ from five days before training until testing. Memory is unaffected in these flies held at the permissive temperature for $t u b$-Gals $80^{t s}\left(18{ }^{\circ} \mathrm{C}\right)$ after $1 \mathrm{x}$ training (right). One-day memory is also unaffected in these flies held at $30{ }^{\circ} \mathrm{C}$ after 10xS training. (B) By contrast, adult-stage specific RNAi downregulation of CREBB proteins in early $\alpha / \beta$ neurons (with two independent RNAi constructs) impairs 1-day memory after 10xS training (left) (also see figure supplement 6). The same LTM is similarly blocked by systemic protein synthesis inhibition induced by CXM feeding (right).

Figure 9. Spaced training activates $\boldsymbol{c r e b B}$ transcription. (A) CREBB expression visualized in dissected brains with $c r e b B$-Gal4 driven UAS-mCD8::GFP (green), counterstained with DLGantibody immunostaining (magenta), and viewed under a confocal microscope. Cross sections of vertical and horizontal MB lobes (center) show more prominent expression in $\alpha / \beta$ neurons than in $\alpha^{\prime} / \beta^{\prime}$ and $\gamma$ neurons (labeled). Scale bar $=10 \mu \mathrm{m}$. (B-C) Promotor activation of $\operatorname{crebB} 24 \mathrm{~h}$ after training reported by de novo Kaede synthesis, estimated by the ratio of new (green, $488 \mathrm{~nm}$ ) and preexisting (red, $561 \mathrm{~nm})$ protein $\left(\% \Delta \mathrm{F} / \overline{\mathrm{F}}_{0}\right)$. For each brain, single optical slices through the MB $\alpha$-lobe tip or ellipsoid body (EB) were imaged under identical conditions. (B) Spaced training stimulates $\operatorname{crebB}$ activity preferentially in the $\alpha$-lobe, in comparison with EB controls. (C) A minimum of $5 \mathrm{xS}$ training cycles are necessary to observe Kaede synthesis reflecting $c r e b B$ activity. Bars represent mean $\pm \mathrm{SE}, n \geq 8$. 
Figure 10. Shn in early $\alpha / \beta$ neurons regulates CREBB dependent LTM formation. (A)

803 Overexpressing Shn proteins in early $\alpha / \beta$ neurons enhances 1-day memory after only 1x training 804 (left) and lasts at least four days ((left center). Gal4-targeted $s h n^{+}$overexpression is induced at the 805 restrictive temperature for $t u b-G a l 80^{t s}\left(30^{\circ} \mathrm{C}\right)$ from five days before training until testing.

806 Memory is unaffected in these flies held at the permissive temperature for $t u b-G a l 80^{t s}\left(18{ }^{\circ} \mathrm{C}\right)$

807 after 1x training (right center) (also see figure supplement 7). One-day memory is also unaffected 808 in these flies held at $30^{\circ} \mathrm{C}$ after $10 x \mathrm{~S}$ training (right). (B) In contrast, adult-stage specific RNAi 809 down-regulation of Shn in early $\alpha / \beta$ neurons (with two independent RNAi constructs) impairs 1810 day memory after 10xS training (left) (also see figure supplement 6). The same LTM is similarly 811 blocked by systemic protein synthesis inhibition induced by CXM feeding (right). (C) Down812 regulating Shn but co-overexpressing CREBB in early $\alpha / \beta$ neurons does not impair 1 -day 813 memory after 10xS training. (D) One-day memory is enhanced after only $1 \mathrm{x}$ training (left) and 814 lasts at least four days (center). Memory is unaffected in flies held at the permissive temperature 815 for $t u b-G a l 80^{t s}\left(18^{\circ} \mathrm{C}\right)$ after $1 x$ training (right). 
bioRxiv preprint doi: https://doi.org/10.1101/2021.06.10.447902; this version posted June 10, 2021. The copyright holder for this preprint (which was not certified by peer review) is the author/funder, who has granted bioRxiv a license to display the preprint in perpetuity. It is made available under aCC-BY 4.0 International license.

A
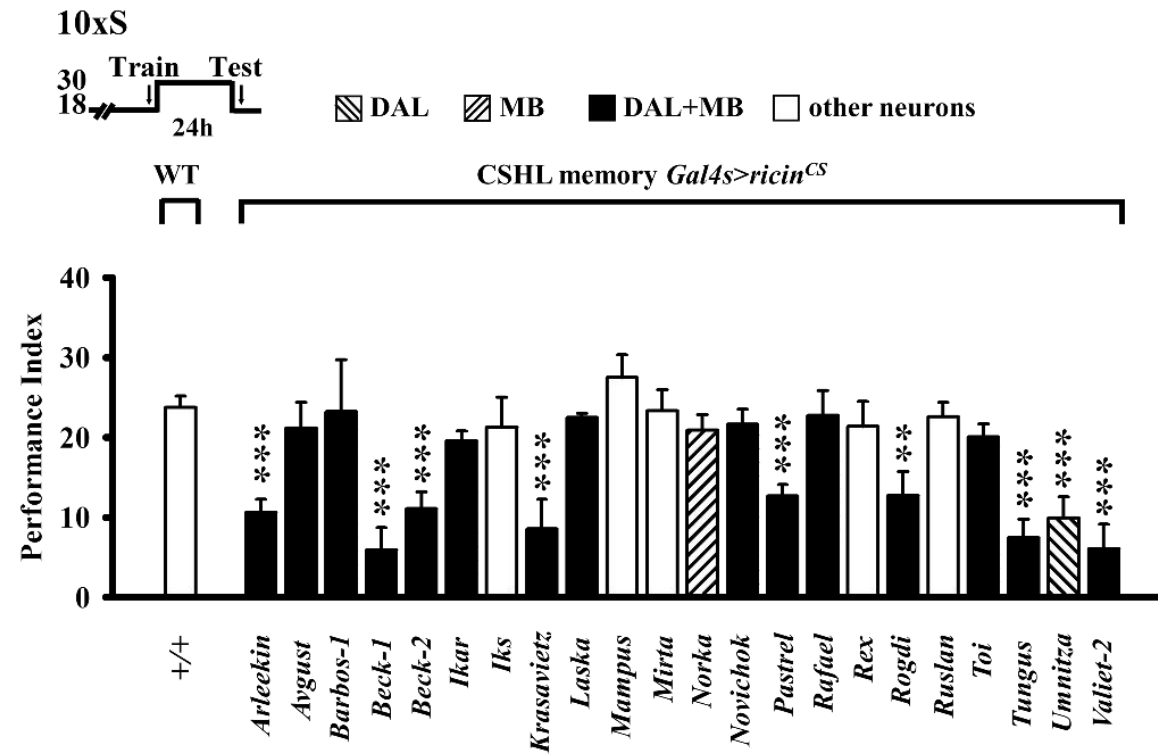

B
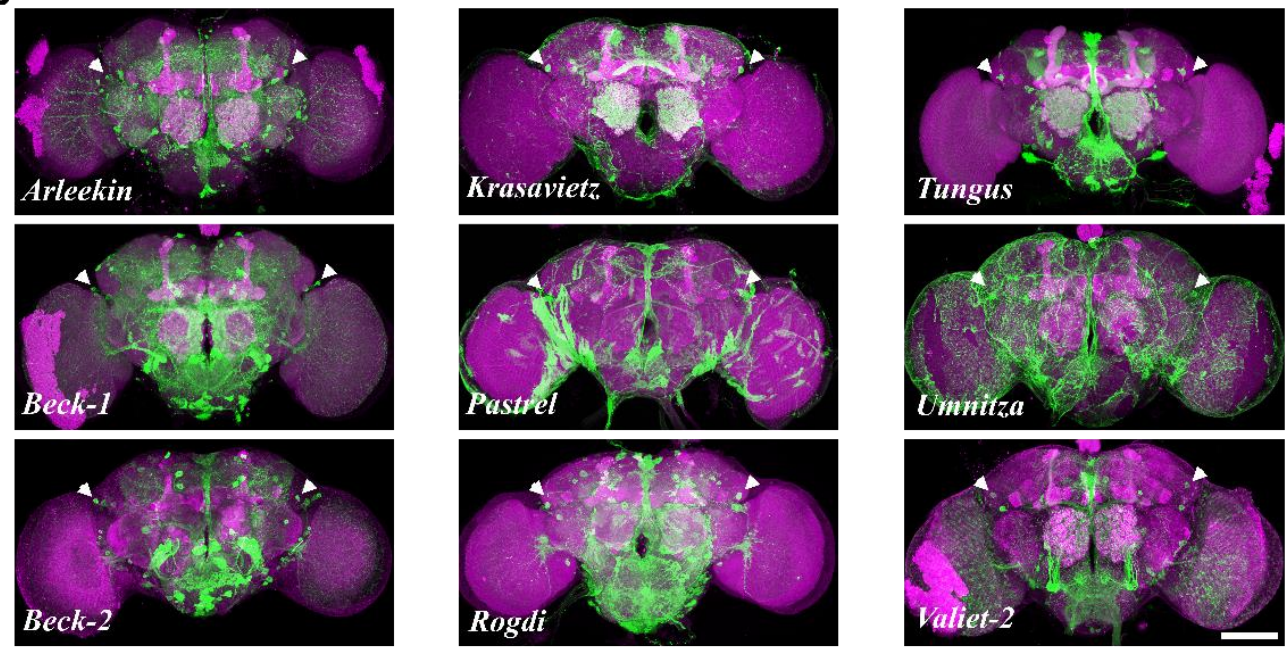

C
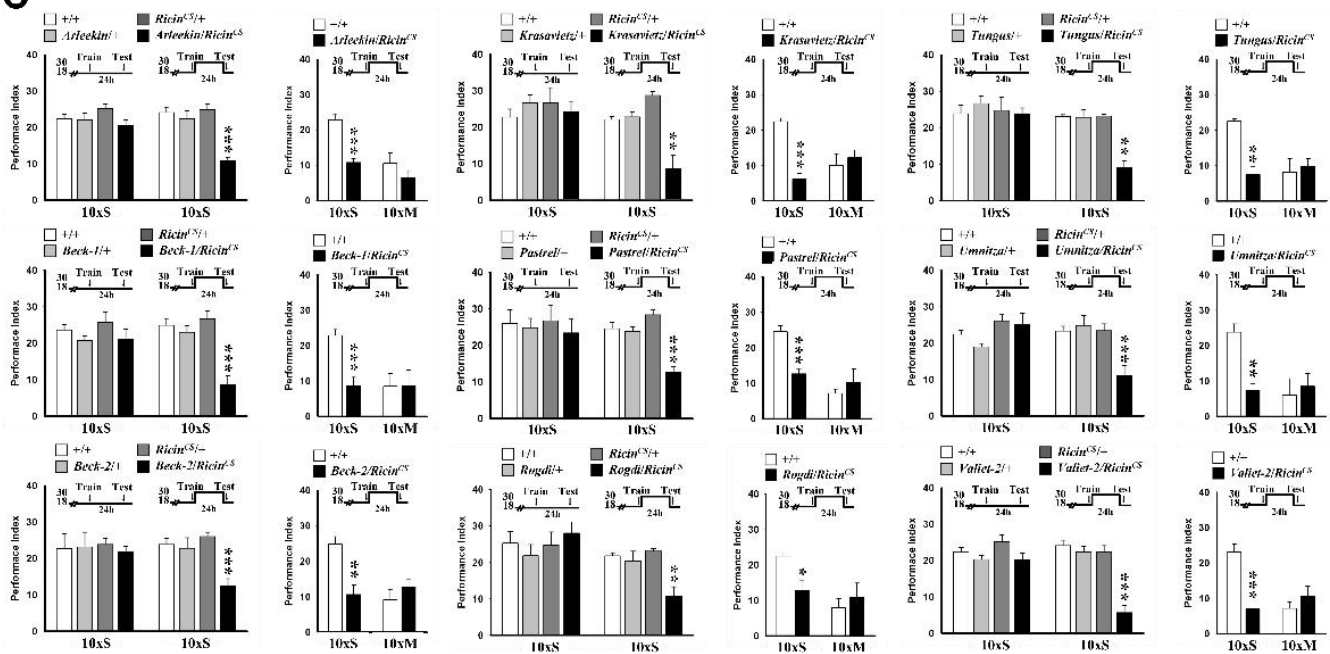

Figure supplement 1. Protein synthesis inhibition in MB and DAL neurons blocks LTM formation. (A) Effects of memory circuit Gal4-targeted Ricin ${ }^{\mathrm{CS}}$ on 1-day memory after ten spaced training cycles (10xS), compared with wild-type $(+/+)$ controls. Cold-sensitive Ricin $^{\mathrm{CS}}$ blocks protein synthesis at the permissive temperature $\left(30{ }^{\circ} \mathrm{C}\right)$ 
835 between training and testing. Inhibition of protein synthesis in eight of 22 Gal4-expressing patterns that include both

$836 \mathrm{MB}$ and DAL neurons and one that includes DAL but not MB neurons (Umnitza) blocks 1-day memory.

837 Interestingly, inhibition of protein synthesis in seven other Gal4-expressing patterns that include both MB and DAL

838 neurons (related to Figure 1) and one that includes MB but not DAL neurons (Norka) have no net effect on LTM. (B)

839 Nine Gal4 expression patterns in which protein synthesis inhibition blocks 1-day memory (A). (C) We observe no

840 LTM effects after Ricin ${ }^{\mathrm{CS}}$ expression in patterns shown above $(\mathbf{B})$ at the restrictive temperature $\left(18{ }^{\circ} \mathrm{C}\right)$ or in flies

841 expressing the nine Gal4 drivers or ricin $^{C S}$ transgene alone (left). Ricin ${ }^{\mathrm{CS}}$ expression in all nine patterns has no effect

842 on 1-day memory after 10xM training (right).

843 In all Extended Data figures, temperature control schedules for behavior experiments are indicated (top). Memory

844 performance indices are calculated as the normalized percent avoidance of shock-paired odor. Bars represent mean \pm

845 SE, $n=8 /$ bar unless otherwise noted. *, $P<0.05$; **, $P<0.01$, ***, $P<0.001$. All images of dissected brains show

846 Gal4-driven $U A S-m C D 8:: G F P$ (green), counterstained with DLG-antibody immunostaining (magenta), as viewed

847 under a confocal microscope. Scale bar $=50 \mu \mathrm{m}$ unless otherwise noted. All fly genotypes are listed in table

848 supplement 1. 


\section{A}
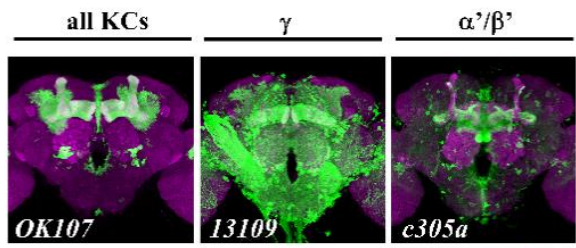

pioneer $\alpha / \beta$
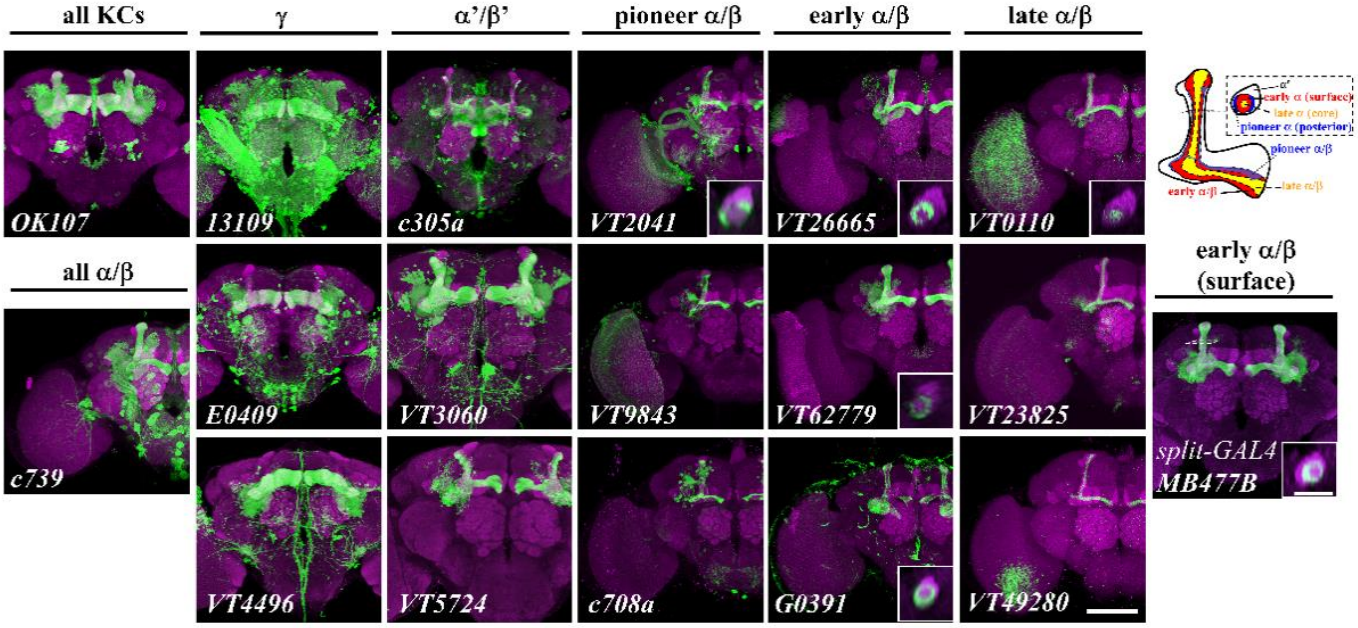

early $\alpha / \beta$ (surface)

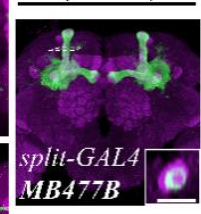

B

10xS

30 Train Test

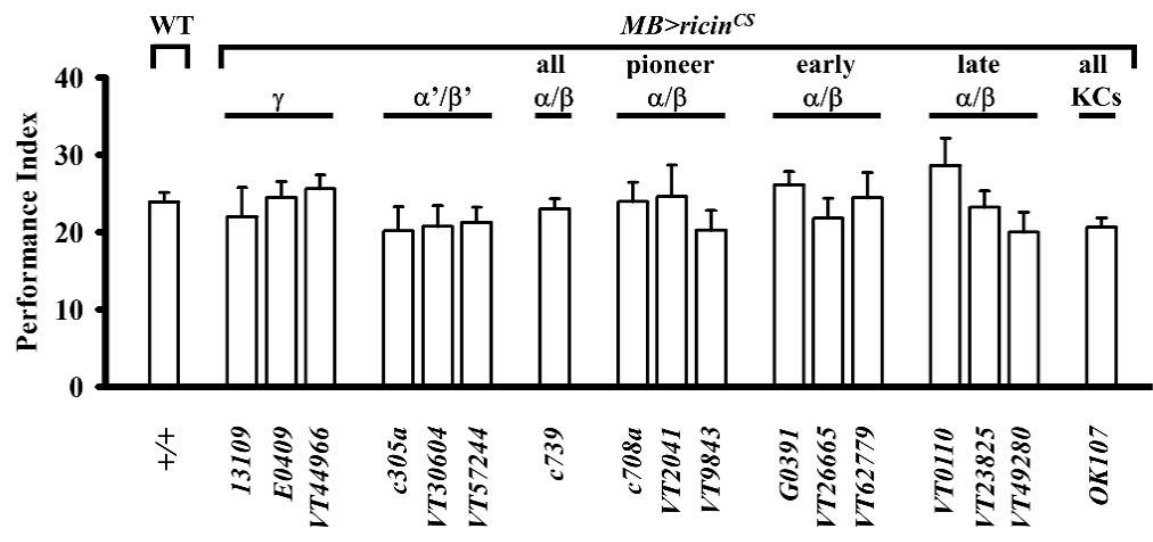

C

3xS

$30 \begin{array}{cc}\text { Train } & \text { Test } \\ 18 & 1\end{array}$

WT

$\sqcap$ all all early

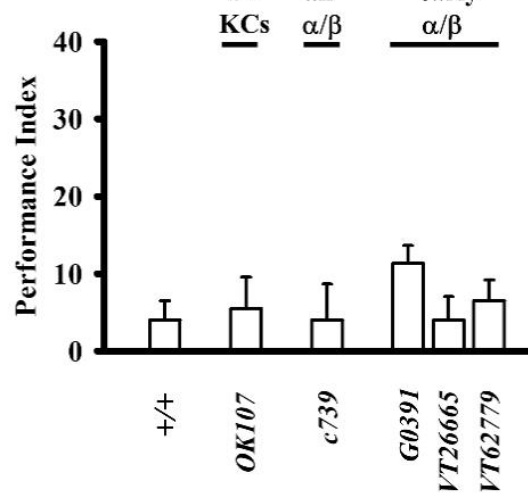

3xM

30 Train Test

WT $\quad M B>$ ricin $^{c s}$

$\sqcap \Gamma_{\text {all all early }}$

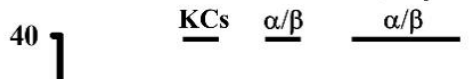

Figure supplement 2. Protein synthesis inhibition in MB neurons does not affect LTM formation after 10xS 
852 subtypes. Spatial distributions of three $\alpha / \beta$ neuron subtypes shown in a schematic representation (right) and in cross

853 section at the vertical lobes (inset). MB split-Gal4 MB477B shows specific expression in early $\alpha / \beta$ (surface) neurons.

854 Scale bar (inset) $=10 \mu \mathrm{m}$. (B) Effects of MB Gal4-targeted Ricin ${ }^{\mathrm{CS}}$ on memory compared with wild-type controls

855 (related to Figure 2). Blocking protein synthesis in MB neurons after 10xS training has no effect on LTM (compare

856 with the memory enhancing effects of protein synthesis inhibition in early $\alpha / \beta$ neurons after $3 \mathrm{xS}$ and $1 \mathrm{x}$ training,

857 Figure 2). (C) Ricin ${ }^{\mathrm{CS}}$ expression in MBs neurons has no effect on memory at the restrictive temperature $\left(18^{\circ} \mathrm{C}\right)$ after

$8583 \mathrm{xS}$ training (left), or at the persmissive temperature $\left(30^{\circ} \mathrm{C}\right)$ after $3 \mathrm{xM}$ training (right). 
A

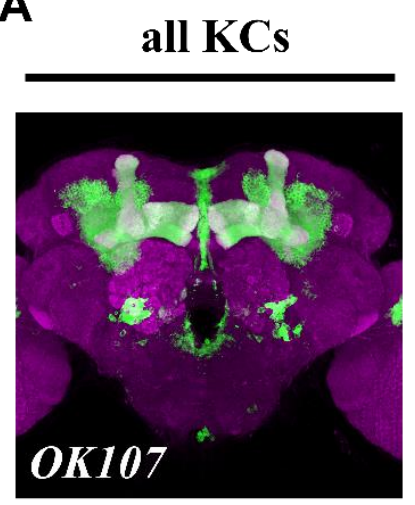

MB-V3

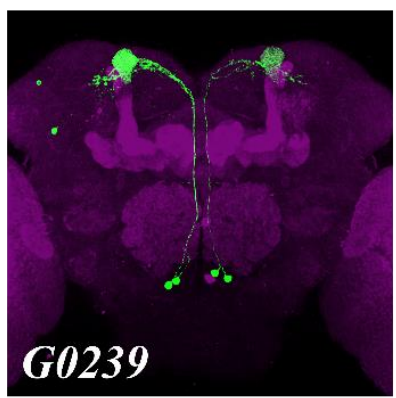

\section{DAL}

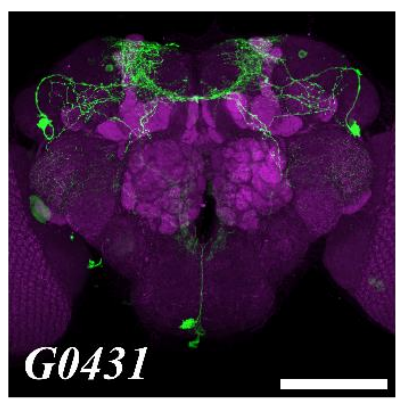

B

$+/+$

$\triangle$ OK107>ricin $^{C S} ;$ ricin $^{C S}$ Whole MB

\section{$10 \times S$}
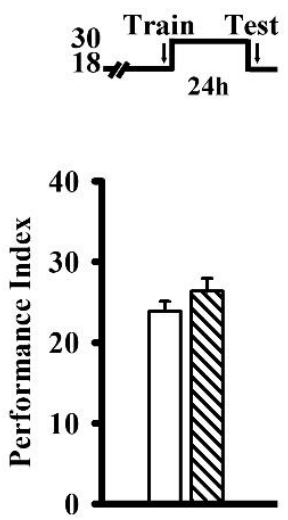

G0239>ricin $^{C S}$; ricin $^{C S}$ MB-V3
G0431>ricin ${ }^{C S} ;$ ricin $^{C S}$

DAL

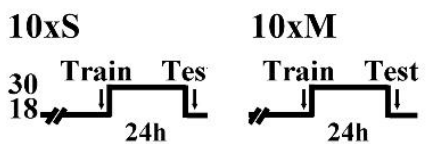

10xS

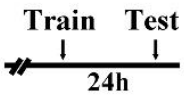

Figure supplement 3. Protein synthesis inhibition in specific extrinsic MB neurons blocks LTM formation. (A)

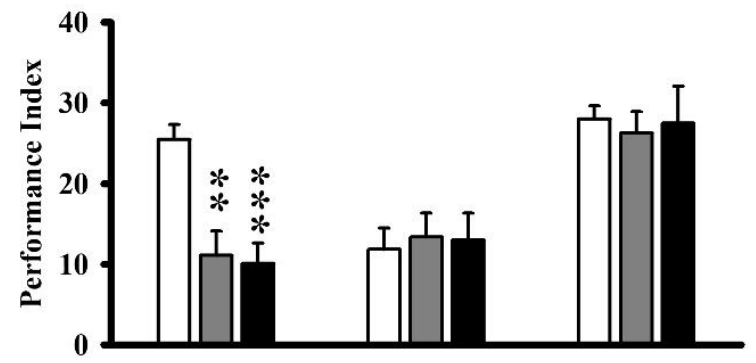
Gal4 expression patterns that delineate intrinsic MB neurons and extrinsic MB-V3 and DAL neurons. (B) Blocking protein synthesis in MB neurons with two copies of active Ricin ${ }^{\mathrm{CS}}$ has no effect on LTM after 10xS training (left). By contrast, blocking protein synthesis in MB-V3 or DAL neurons inhibits LTM after 10xS training (right), but not after $10 x M$ training or after $10 x S$ training when flies are held at the restrictive temperature $\left(18{ }^{\circ} \mathrm{C}\right)$. 


\section{A}

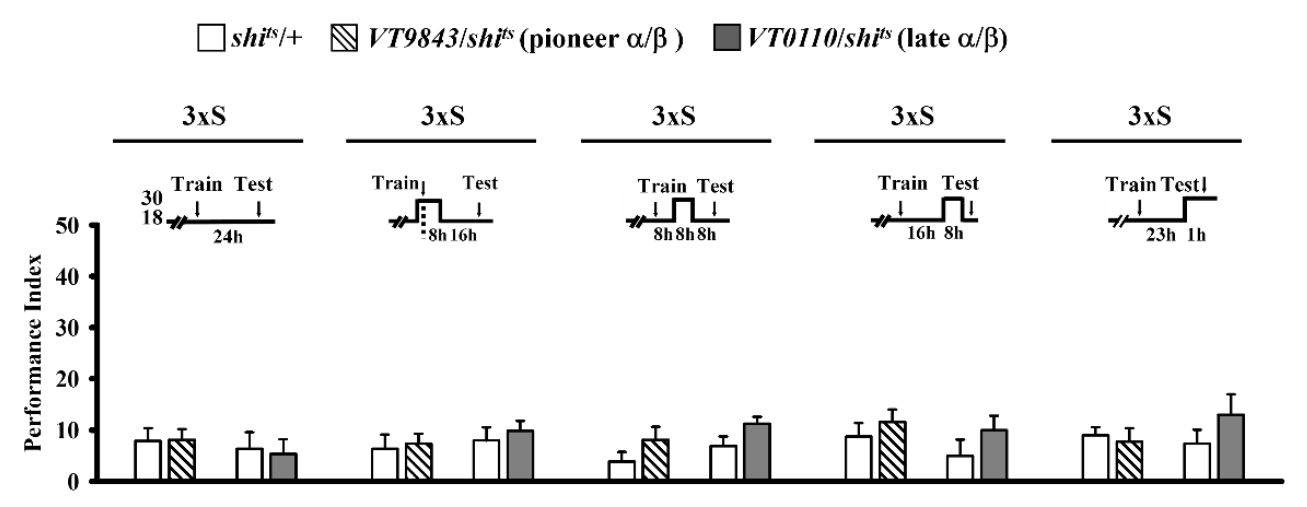

B

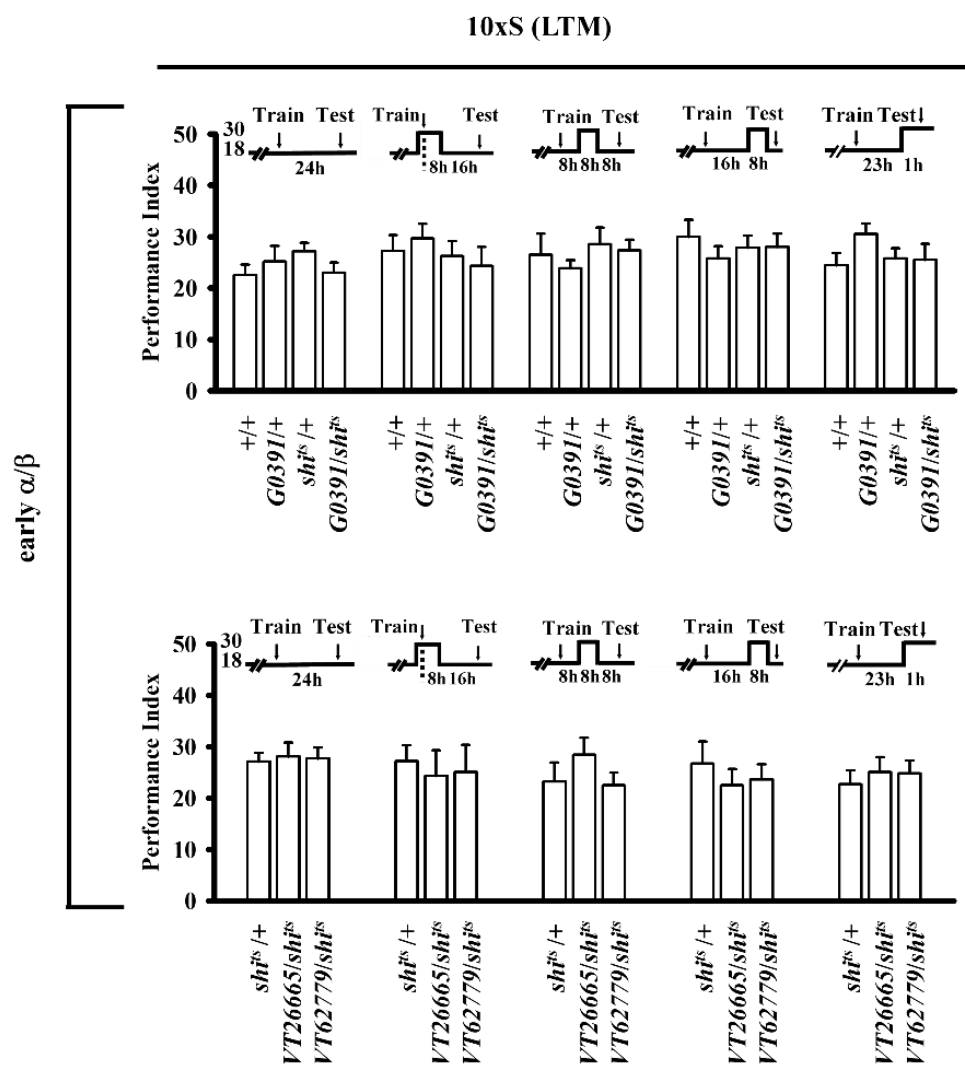
neurons during sequential 8-h time windows after subthreshold 3xS training has no effect on memory. (B) Blocking neural transmission from early $\alpha / \beta$ neurons during sequential 8 -h time windows after $10 x \mathrm{x}$ training has no effect on

872 memory. By comparison, blocking transmission from early $\alpha / \beta$ neurons after $3 x S$ training enhances memory (Figure 873 4). 


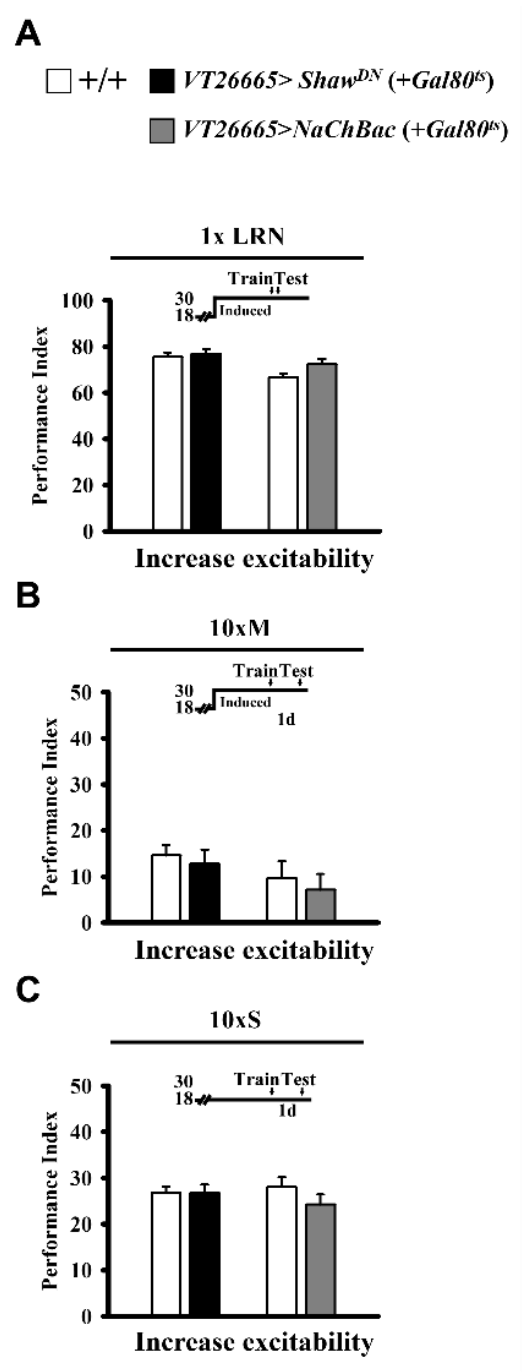

Figure supplement 5. Increasing membrane excitability in early $\alpha / \beta$ neurons and effects on memory formation.

Early $\alpha / \beta$ Gal4-targeted expression of $\mathrm{K}^{+}$and $\mathrm{Na}^{+}$channel proteins is induced at the restrictive temperature for the tub-Gal80 $0^{t s}$ inhibitor $\left(30^{\circ} \mathrm{C}\right)$ from five days prior to training until testing. Experimental groups are compared with

878 wild-type (+/+) controls. (A) Shaw ${ }^{D N}$ and NaChBac overexpression increase neural activity in early $\alpha / \beta$ neurons but 879 have no effects on immediate memory after 1x training. (B) Similarly, elevated neural activity has no effect on 1-day 880 memory after 10xM training. By comparison, elevated neural activity impairs 1-day memory after 10xS training

881 (Figure 5). (C) Channel proteins are not induced in flies maintained at the permissive temperature for the $t u b$-Gal80 $0^{t s}$ 882 inhibitor $\left(18^{\circ} \mathrm{C}\right)$ and show no differences in memory after 10xS training. 
A

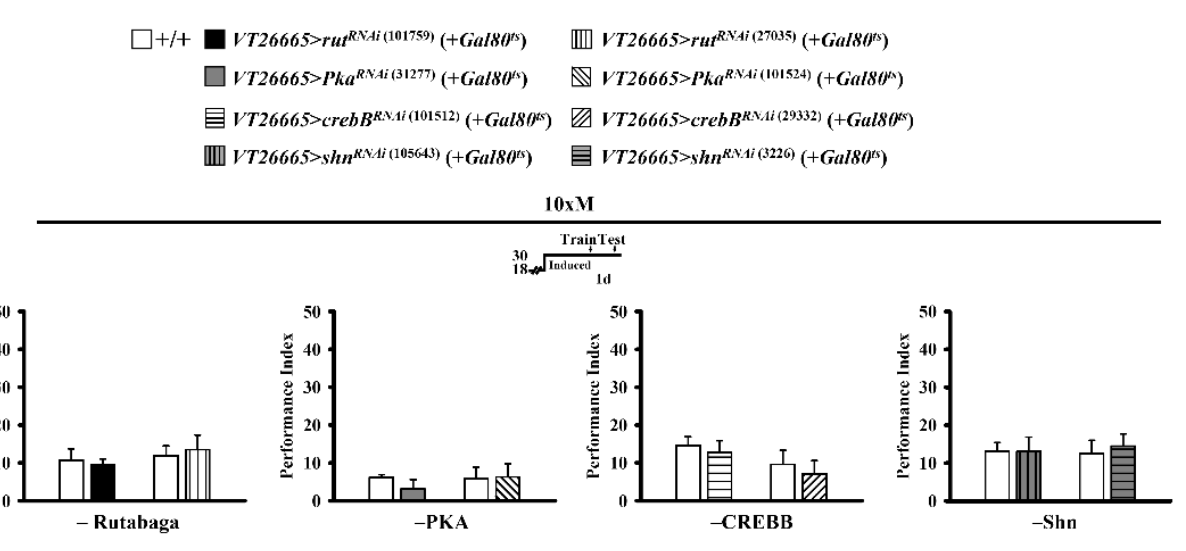

B

10xS

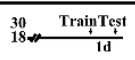
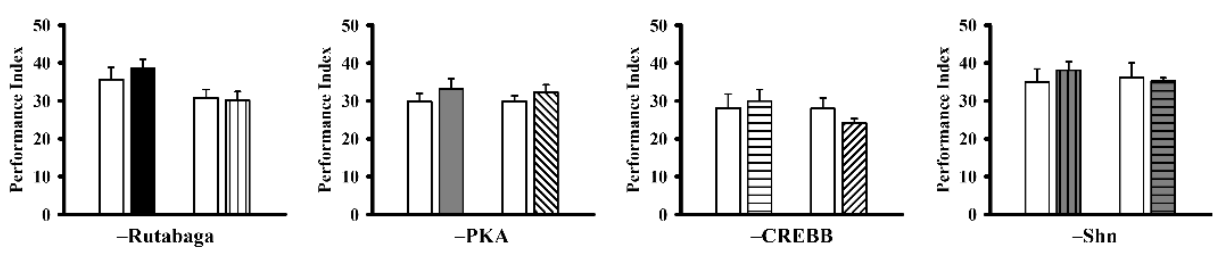

C
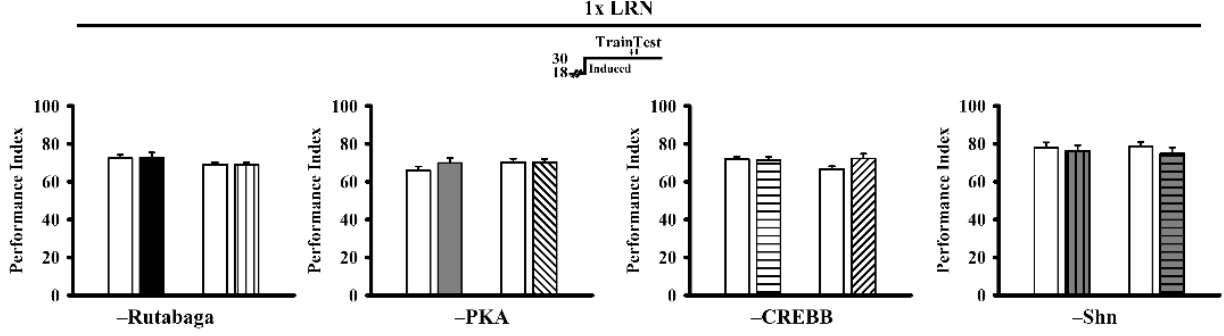

Figure supplement 6. Down-regulation of CREBB, Rutabaga (AC), PKA and Schnurri (Shn) in early

$\alpha / \beta$ neurons and effects on memory formation. (A) Adult-stage specific RNAi down-regulation of these proteins

(encoded by rut, $P k a, c r e b B$ and shn) in early $\alpha / \beta$ neurons (two RNAi constructs each) have no effects on 1-day memory after 10xM training. Gal4-targeted RNAi specific for each gene is induced at the restrictive temperature for tub-Gal8 $80^{t s}\left(30^{\circ} \mathrm{C}\right)$ from five days prior to training until testing. Experimental groups are compared with wild-type $(+/+)$ controls. (B) Proteins are not down-regulated in flies maintained at the permissive temperature for the tub-

Gal $80^{t s}$ inhibitor $\left(18^{\circ} \mathrm{C}\right)$ and there are no differences in memory in comparison with control flies after 10xS training.

(C) Down regulation of all proteins in early $\alpha / \beta$ neurons has no effect on immediate memory after $1 \mathrm{x}$ training. By comparison, overexpressing AC, PKA, CREBB and Shn in early $\alpha / \beta$ neurons enhances 1 -day memory after only $1 \mathrm{x}$ training (Figure 6-8 and 10). 


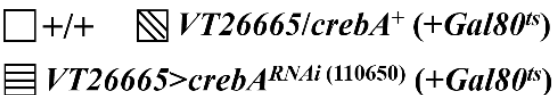

A

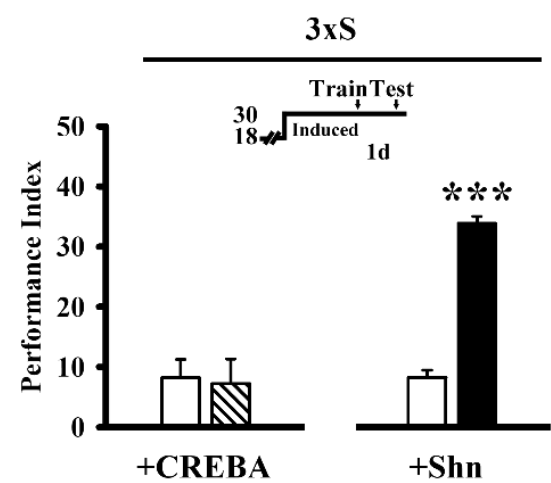

B

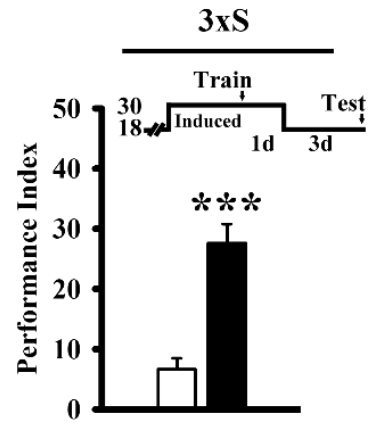

+ Shn
$V T 26665 / \mathrm{shn}^{+(403 ; 401)}\left(+G a l 80^{t s}\right)$

C

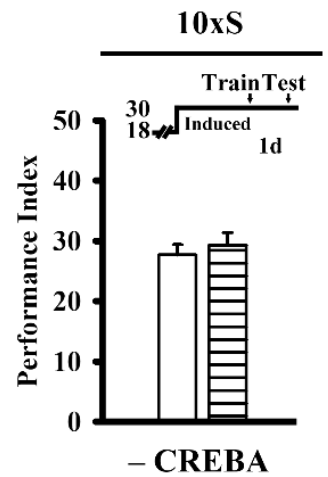

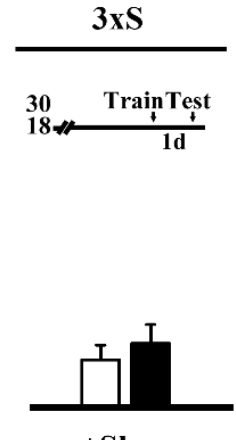

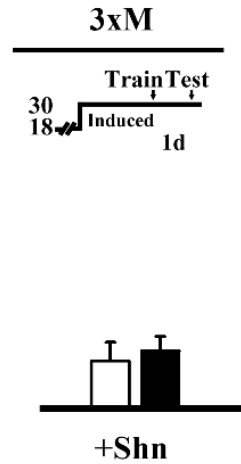

Figure supplement 7. Overexpression of Shn but not CREBA protein in early $\alpha / \beta$ neurons enhances LTM

formation. (A) Overexpressing Shn but not CREBA in early $\alpha / \beta$ neurons enhances 1 -day memory after $3 \mathrm{xS}$ training. Gal4-targeted crebA or shn overexpression is induced at the restrictive temperature for $t u b-G a l 80^{t s}\left(30{ }^{\circ} \mathrm{C}\right)$ from five days prior to training until testing. (B) Enhanced memory lasts at least four days (left). Memory is unaffected in these flies held at the permissive temperature for $t u b-G a l 80^{t s}\left(18{ }^{\circ} \mathrm{C}\right)$ after $3 \mathrm{xS}$ training (center), or at the restrictive temperature $\left(30^{\circ} \mathrm{C}\right)$ after $3 \mathrm{xM}$ training (right). (C) Adult-stage specific down-regulation of CREBA protein in early $\alpha / \beta$ neurons has no effect on 1 -day memory after $10 x S$ training. 

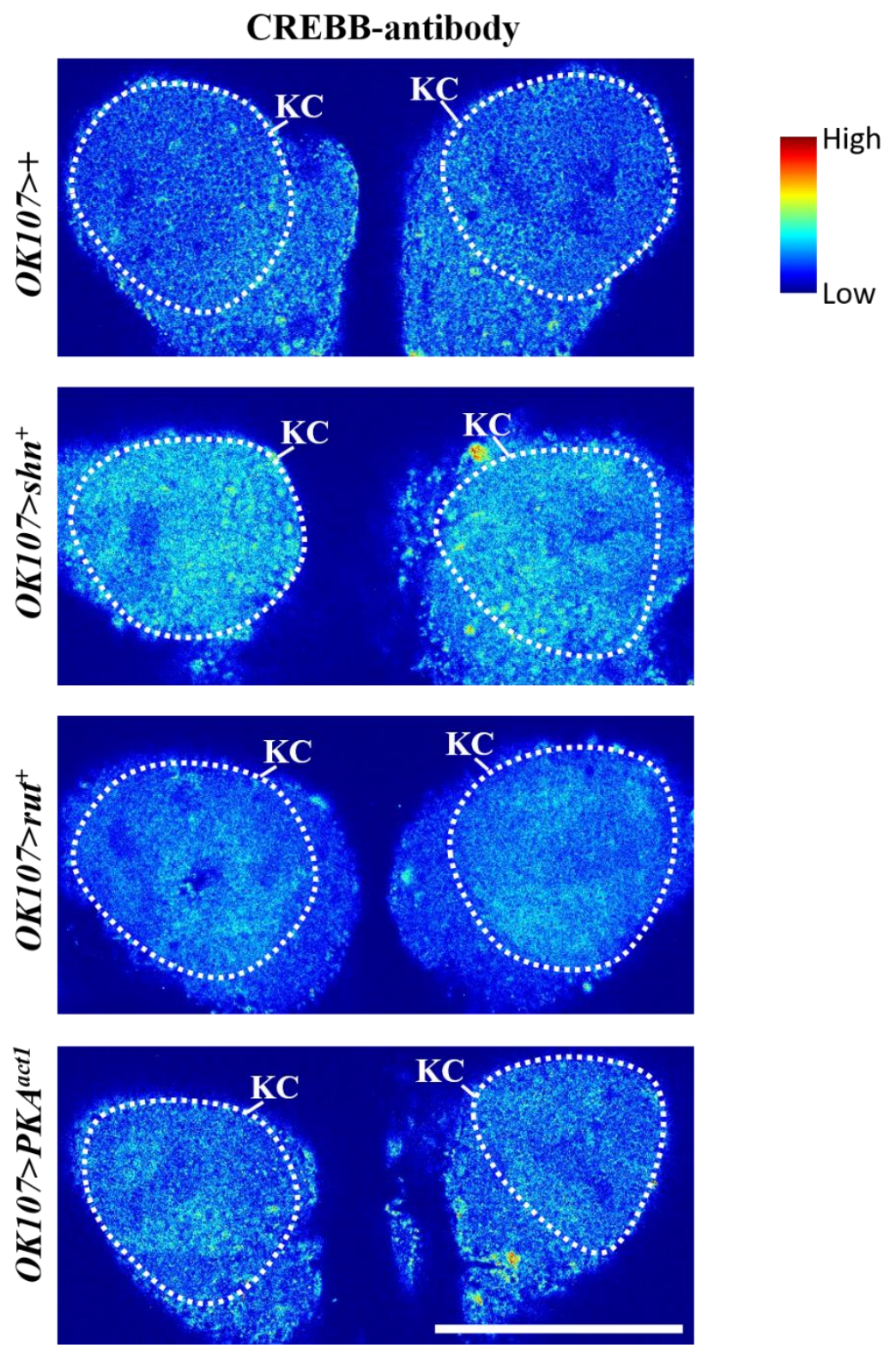

905 Figure supplement 8. Transgene over-expression and CREBB protein levels in MB Kenyon cells. Gal4-OK107906 driven shn over-expression led to elevated CREBB protein levels (second from top) in comparison with the control 907 (top). Over-expression of rut and PKA had only minor impact on CREBB expression (second from bottom and 908 bottom, respectively). Confocal images of Drosophila MB Kenyon cell bodies (encircled by the white dotted line) 909 show the intensity of CREBB immunostaining in a jet colormap. 
bioRxiv preprint doi: https://doi.org/10.1101/2021.06.10.447902; this version posted June 10, 2021. The copyright holder for this preprint (which was not certified by peer review) is the author/funder, who has granted bioRxiv a license to display the preprint in perpetuity. It is made available under aCC-BY 4.0 International license.

\begin{tabular}{|c|c|c|c|c|c|c|c|c|c|}
\hline & $\gamma d$ & $\gamma m$ & $\alpha^{\prime} / \beta^{\prime}$ ap & $\alpha^{\prime} / \beta^{\prime} m$ & $\begin{array}{c}\alpha / \beta \\
\text { pioneer } \\
\text { (posterior) }\end{array}$ & $\begin{array}{c}\alpha / \beta \\
\text { early } \\
\text { (surface) }\end{array}$ & $\begin{array}{c}\alpha / \beta \\
\text { late } \\
\text { (core) }\end{array}$ & $\overline{D A L}$ & EB \\
\hline Barbos-1 & - & + & - & - & - & +++ & +++ & +++ & + \\
\hline Ikar & - & + & + & + & - & +++ & +++ & +++ & +++ \\
\hline Laska & - & + & + & + & - & +++ & +++ & +++ & ++ \\
\hline Rafael & - & ++ & - & - & - & +++ & +++ & +++ & - \\
\hline Toi & - & + & - & - & - & +++ & +++ & +++ & + \\
\hline Arleekin & - & - & ++ & ++ & - & ++ & +++ & +++ & + \\
\hline Beck-1 & - & - & - & - & - & - & + & +++ & +++ \\
\hline Beck-2 & - & - & - & - & - & - & + & +++ & +++ \\
\hline Umnitza & + & + & - & - & - & + & - & +++ & + \\
\hline Valiet-2 & - & - & - & - & - & - & ++ & +++ & - \\
\hline
\end{tabular}

915 Table supplement 1. CSHL memory Gal4 patterns. Table shows Gal4 targeted GFP intensity was graded as strong

$916(+++)$, intermediate (++), weak (+), absence (-) or non-distinguishable (N.D.). DAL, dorsal anterior lateral neuron;

917 EB, ellipsoid body. 
bioRxiv preprint doi: https://doi.org/10.1101/2021.06.10.447902; this version posted June 10 2021. The copyright holder for this preprint (which was not certified by peer review) is the author/funder, who has granted bioRxiv a license to display the preprint in perpetuity. It is made available under aCC-BY 4.0 International license.

\section{Fly genotypes utilized in experiments}

\begin{tabular}{llll}
\hline Symbol & Genotype \& Chromosome & Description & Source \\
\hline$+/+$ & Canton $S$ w w1118 (isolCJ) & Wild-type & Tully et al.,1994
\end{tabular}

\section{Gal4/Gal80 Transgenes}

\begin{tabular}{|c|c|c|c|}
\hline$V T 44966$ & $P\{V T 44966-$ Gal4\}attP2 on Chr 3 & Gal4 driver, strong in $\gamma$ neurons & $\mathrm{VDRC}^{\mathrm{a}}$ \\
\hline VT30604 & $P\{V T 30604-$ Gal 4$\} a t t P 2$ on $\mathrm{Chr} 3$ & Gal4 driver, specific in $\alpha^{\prime} / \beta^{\prime}$ neurons & $\mathrm{VDRC}^{\mathrm{a}}$ \\
\hline VT57244 & $P\{V T 57244-G a l 4\} a t t P 2$ on $\mathrm{Chr} 3$ & Gal4 driver, specific in $\alpha^{\prime} / \beta^{\prime}$ neurons & $\mathrm{VDRC}^{\mathrm{a}}$ \\
\hline VT2041 & $P\{V T 2041-$ Gal $\}$ attP2 on Chr 3 & Gal4 driver, specific in pioneer $\alpha / \beta$ neurons & VDRC \\
\hline VT9843 & P\{VT9843-Gal4 $\}$ attP2 on Chr 3 & Gal4 driver, specific in pioneer $\alpha / \beta$ neurons & $\mathrm{VDRC}^{\mathrm{a}}$ \\
\hline VT26665 & $P\{V T 26665$-Gal4\}attP2 on $\mathrm{Chr} 3$ & Gal4 driver, specific in early $\alpha / \beta$ neurons & VDRCa \\
\hline VT62779 & $P\{V T 62779-G a l 4\}$ attP2 on $\mathrm{Chr} 3$ & Gal4 driver, specific in early $\alpha / \beta$ neurons & $\mathrm{VDRC}^{\mathrm{a}}$ \\
\hline VT0110 & $P\{$ VT0110-Gal4 $\}$ attP2 on Chr 3 & Gal4 driver, specific in late $\alpha / \beta$ neurons & VDRCa \\
\hline$V T 23825$ & $P\{V T 23825$-Gal4\}attP2 on $\mathrm{Chr} 3$ & Gal4 driver, specific in late $\alpha / \beta$ neurons & $\mathrm{VDRC}^{\mathrm{a}}$ \\
\hline VT49280 & $P\{V T 49280-$ Gal 4$\}$ attP2 on $\mathrm{Chr} 3$ & Gal4 driver, specific in late $\alpha / \beta$ neurons & VDRC \\
\hline OK107 & $P\{G a w B\} O K 107$ on $\mathrm{Chr} 4$ & Gal4 driver, strong in all $\mathrm{MB}$ neurons & BDSC $^{\text {b }}$ Lin et al., 2007 \\
\hline$c 739$ & $P\{G a w B\} c 739$ on $\mathrm{Chr} 3$ & Gal4 driver, strong in all $\alpha / \beta$ neurons & BDSC $^{\text {b; }}$ Lin et al., 2007 \\
\hline$c 305 a$ & $P\{G a w B\} c 305 a$ on $\mathrm{Chr} 1$ & Gal4 driver, strong in $\alpha^{\prime} / \beta^{\prime}$ neurons & BDSC $^{\text {b }}$ Lin et al., 2007 \\
\hline$c 708 a$ & $P\{G a w B\} c 708 a$ on $\mathrm{Chr} 1$ & Gal4 driver, specific in pioneer $\alpha / \beta$ neurons & BDSC $^{b} ;$ Lin et al., 2007 \\
\hline E0409 (103496) & $P\{G a w B\}$ fru $[N P 0021]$ on $\mathrm{Chr} 3$ & Gal4 driver, strong in $\gamma$ neurons & DGRC' $^{c}$ Lee et al., 2011 \\
\hline Arleekin & $P\{$ GawB $\}$ Arleekin on Chr 3 & CSHL memory Gal4 driver & Dubnau et al., 2003 \\
\hline Avgust & $P\{G a w B\}$ Avgust on $\mathrm{Chr} 2$ & CSHL memory Gal4 driver & Dubnau et al., 2003 \\
\hline Barbos-1 & $P\{$ GawB $\}$ Barbos- 1 on $\mathrm{Chr} 2$ & CSHL memory Gal4 driver & Dubnau et al., 2003 \\
\hline Beck-1 & $P\{$ GawB $\}$ Beck-1 on $\mathrm{Chr} 2$ & CSHL memory Gal4 driver & Dubnau et al., 2003 \\
\hline Beck-2 & $P\{G a w B\}$ Beck- 2 on $\mathrm{Chr} 2$ & CSHL memory Gal4 driver & Dubnau et al., 2003 \\
\hline Ikar & $P\{G a w B\} I k a r$ on $\mathrm{Chr} 3$ & CSHL memory Gal4 driver & Dubnau et al., 2003 \\
\hline Iks & $P\{G a w B\}$ Iks on Chr 3 & CSHL memory Gal4 driver & Dubnau et al., 2003 \\
\hline Krasavietz & $P\{$ GawB $\}$ Krasavietz on $\mathrm{Chr} 3$ & CSHL memory Gal4 driver & Dubnau et al., 2003 \\
\hline Laska & $P\{G a w B\}$ Laska on $\mathrm{Chr} 3$ & CSHL memory Gal4 driver & Dubnau et al., 2003 \\
\hline Mampus & $P\{$ GawB $\}$ Mampus on $\mathrm{Chr} 2$ & CSHL memory Gal4 driver & Dubnau et al., 2003 \\
\hline Mirta & $P\{$ GawB $\}$ Mirta on Chr 3 & CSHL memory Gal4 driver & Dubnau et al., 2003 \\
\hline Norka & $P\{G a w B\}$ Norka on Chr 3 & CSHL memory Gal4 driver & Dubnau et al., 2003 \\
\hline Novichok & $P\{$ GawB $\}$ Novichok on Chr 3 & CSHL memory Gal4 driver & Dubnau et al., 2003 \\
\hline Pastrel & $P\{$ GawB $\}$ Pastrel on Chr 3 & CSHL memory Gal4 driver & Dubnau et al., 2003 \\
\hline Rafael & $P\{$ GawB $\}$ Rafael on $\mathrm{Chr} 3$ & CSHL memory Gal4 driver & Dubnau et al., 2003 \\
\hline $\operatorname{Rex}$ & $P\{$ GawB $\}$ Rex on Chr 2 & CSHL memory Gal4 driver & Dubnau et al., 2003 \\
\hline Rogdi & $P\{$ GawB $\}$ Rogdi on $\mathrm{Chr} 3$ & CSHL memory Gal4 driver & Dubnau et al., 2003 \\
\hline Ruslan & $P\{G a w B\}$ Ruslan on $\mathrm{Chr} 3$ & CSHL memory Gal4 driver & Dubnau et al., 2003 \\
\hline Toi & $P\{G a w B\} T o i$ on $\mathrm{Chr} 3$ & CSHL memory Gal4 driver & Dubnau et al., 2003 \\
\hline Tungus & $P\{$ GawB $\}$ Tungus on $\mathrm{Chr} 2$ & CSHL memory Gal4 driver & Dubnau et al., 2003 \\
\hline Umnitza & $P\{$ GawB $\}$ Umnitza on Chr 2 & CSHL memory Gal4 driver & Dubnau et al., 2003 \\
\hline Valiet-2 & $P\{$ GawB $\}$ Valiet -2 on $\mathrm{Chr} 2$ & CSHL memory Gal4 driver & Dubnau et al., 2003 \\
\hline $13109(G 0451)$ & $P\{G T 1\} B G 00015$ on $\mathrm{Chr} 1$ & Gal4 driver, strong in $\gamma$ neurons & BDSC $^{b} ;$ Lin et al., 2007 \\
\hline G0391 (12795) & $P\{G T 1\} B G 02525$ on $\mathrm{Chr} 3$ & Gal4 driver, specific in early $\alpha / \beta$ neurons & BDSC $^{\text {b; }}$ Lin et al., 2007 \\
\hline G0239 (12639) & $P\{G T 1\} B G 01228$ on $\mathrm{Chr} 2$ & Gal4 driver, specific in $\mathrm{MB}-\mathrm{V} 3$ neurons & BDSC $^{\text {b; }}$ Pai et al., 2013 \\
\hline G0431 (12837) & $P\{G T 1\} B G 02822$ on $\mathrm{Chr} 3$ & Gal4 driver, specific in DAL neurons & BDSC $^{\text {b; }}$ Chen et al., 2012 \\
\hline$M B 477 B$ & $\begin{array}{l}P\{R 44 E 04-p 65 . A D\} \text { attP40 on Chr } 2 \\
P\{R 26 E 07-G A L 4 . D B D\} \text { attP2 on } \mathrm{Chr} 3\end{array}$ & Split-Gal4 driver, specific in early $\alpha / \beta$ neurons & Aso et al., 2014 \\
\hline $\operatorname{crebB}$ & $P\{$ crebB-Gal $\}$ attP 40 on Chr 2 & crebB promoter Gal4 driver & This study \\
\hline
\end{tabular}

This study 
bioRxiv preprint doi: https://doi.org/10.1101/2021.06.10.447902; this version posted June 10, 2021. The copyright holder for this preprint (which was not certified by peer review) is the author/funder, who has granted bioRxiv a license to display the preprint in perpetuity. It is made available under aCC-BY 4.0 International license.

\begin{tabular}{|c|c|c|c|}
\hline cry-Gal80 & $P\{c r y-G a l 80\}$ on $\mathrm{Chr} 3$ & $\begin{array}{l}\text { Inhibit Gal4 with DAL-specific (cryptochrome } \\
\text { promoter) expression of Gal80 }\end{array}$ & $\begin{array}{l}\text { Stoleru et al., 2004; } \\
\text { Chen et al., } 2012\end{array}$ \\
\hline MB-Gal80 & $P\{m b 247-G A L 80\}$ on $\mathrm{Chr} 2$ & $\begin{array}{l}\text { Inhibit Gal4 with MB-specific ( } m b 247 \text { promoter) } \\
\text { expression of Gal } 80\end{array}$ & Krashes et al., 2008 \\
\hline tub-Gal80ts & $P\left\{t u b P-G A L 80^{\prime s}\right\} 20$ on $\mathrm{Chr} 2$ & $\begin{array}{l}\text { Inhibit Gal } 4 \text { with tubulin promoter drive } \\
\text { temperature-sensitive Gal } 80\end{array}$ & $\mathrm{BDSC}^{\mathrm{b}}$ \\
\hline \multicolumn{4}{|c|}{ UAS Transgenes } \\
\hline GFP & $\begin{array}{l}P\{U A S-m C D 8:: G F P\} L L 5, \\
P\{U A S-m C D 8:: G F P\} 2 \text { on } \mathrm{Chr} 2 ; \\
P\{U A S-m C D 8:: G F P . L\} L L 6 \text { on } \mathrm{Chr} 3\end{array}$ & $\begin{array}{l}\text { membrane-targeted green fluorescent protein } \\
\text { (GFP) }\end{array}$ & $\mathrm{BDSC}^{\mathrm{b}}$ \\
\hline Kaede & $P\{U A S$-kaede $\}$ on $\mathrm{Chr} 3$ & $\begin{array}{l}\text { photoconvertible fluorescent protein to report de } \\
\text { novo protein synthesis }\end{array}$ & Chen et al., 2012 \\
\hline ricin $^{C S}$ & $\begin{array}{l}P\left\{U A S \text {-ricin }{ }^{C S}\right\} \text { on } \mathrm{Chr} 2 \\
P\{U A S \text {-ricin } \\
C S\} \text { on } \mathrm{Chr} 3\end{array}$ & $\begin{array}{l}\text { cold-sensitive ribosome-inactivating toxin to } \\
\text { acutely inhibit protein synthesis }\end{array}$ & $\begin{array}{l}\text { Pai et al., 2013; } \\
\text { Chen et al., 2012; } \\
\text { Wu et al., 2017; } \\
\text { Moffat et al.,,1992; } \\
\text { Allen et al., } 2002\end{array}$ \\
\hline$s h i^{t s}$ & $P\left\{U A S-s h i^{t s}\right\}$ on $\mathrm{Chr} 3$ & $\begin{array}{l}\text { temperature-sensitive dominant-negative form } \\
\text { of Dynamin to block synaptic transmission }\end{array}$ & Dubnau et al., 2001 \\
\hline $\operatorname{Shaw}^{D N}$ & $P\left\{U A S-S h a w^{D N}\right\}$ on $\mathrm{Chr} 2$ & dominant-negative $\mathrm{K}+$ channel & Hodge et al., 2005 \\
\hline $\mathrm{NaChBac}$ & P $\{$ UAS-NaChBac $\}$ on $\mathrm{Chr} 2$ & bacterial $\mathrm{Na}+$ channel & Joiner et al., 2006 \\
\hline Shaw & $P\{U A S-S h a w\}$ on $\mathrm{Chr} 2$ & $\mathrm{~K}+$ channel & Hodge et al., 2005 \\
\hline Kir2.1::GFP & $P\{U A S-K i r 2.1:: G F P\}$ on $\mathrm{Chr} 3$ & inward-rectifying $\mathrm{K}+$ channel; PIP2 dependent & Joiner et al., 2006 \\
\hline$c r e b B$ & $P\{U A S$-crebB $\}$ on $\mathrm{Chr} 3$ & cAMP response element binding protein (crebB) & $\mathrm{BDSC}^{\mathrm{b}}$ \\
\hline$r u t^{+}$ & $\begin{array}{l}P\{U A S-r u t\} 2 \text { on } \mathrm{Chr} 2 \\
P\{U A S-r u t\} 1 \text { on } \mathrm{Chr} 3\end{array}$ & wild type rutabaga ${ }^{+}$, adenylyl cyclase (AC) & $\mathrm{BDSC}^{\mathrm{b}}$ \\
\hline$P k a^{a c t l}$ & $P\left\{U A S-P k a^{a c t 1}\right\}$ on $\mathrm{Chr} 2$ & $\begin{array}{l}\text { constitutively active subunit of cAMP- } \\
\text { dependent protein kinase (PKA) }\end{array}$ & Joiner et al., 2006 \\
\hline $\mathrm{creb}^{+}$ & & cAMP response element binding protein (crebA) & $\mathrm{BDSC}^{\mathrm{b}}$ \\
\hline$s h n^{+}$ & $\begin{array}{l}P\{U A S-s h n\} 403 \text { on } \mathrm{Chr} 2 \\
P\{U A S-s h n\} 401 \text { on } \mathrm{Chr} 3\end{array}$ & $\begin{array}{l}\text { wild type schnurri }{ }^{+} \text {, zinc finger } \mathrm{C} 2 \mathrm{H} 2 \\
\text { transcription factor }\end{array}$ & Marty et al., 2000 \\
\hline$v 101512$ & $P\{K K 108927\}$ VIE- $260 B$ on $\mathrm{Chr} 2$ & crebB RNA interference & $\mathrm{VDRC}^{\mathrm{a}}$ \\
\hline$v 101759$ & $P\{K K 109441\}$ VIE- $260 B$ on $\mathrm{Chr} 2$ & rutabaga (AC) RNA interference & $\mathrm{VDRC}^{\mathrm{a}}$ \\
\hline$v 101524$ & $P\{K K 108966\}$ VIE- $260 B$ on $\mathrm{Chr} 2$ & Pka RNA interference & $\mathrm{VDRC}^{\mathrm{a}}$ \\
\hline$v 105643$ & $P\{K K 101278\} V I E-260 B$ on $\mathrm{Chr} 2$ & schnurri RNA interference & $\mathrm{VDRC}^{\mathrm{a}}$ \\
\hline$v 3226$ & $P\{G D 1644\} v 3226$ on $\mathrm{Chr} 3$ & schnurri RNA interference & $\mathrm{VDRC}^{\mathrm{a}}$ \\
\hline 29332 & P\{TRiP.JF02494\}attP2 on Chr 3 & crebB RNA interference & $\mathrm{BDSC}^{\mathrm{b}}$ \\
\hline 27035 & P\{TRiP.JF02361\}attP2 on Chr 3 & rutabaga (AC) RNA interference & $\mathrm{BDSC}^{\mathrm{b}}$ \\
\hline 31277 & P\{TRiP.JF01218\}attP2 on Chr 3 & PKA RNA interference & $\mathrm{BDSC}^{\mathrm{b}}$ \\
\hline
\end{tabular}

a Vienna Drosophila Resource Center; ${ }^{\mathrm{b}}$ Bloomington Drosophila Stock Center; ${ }^{\mathrm{c}}$ KYOTO Stock Center.

Table supplement 2. Fly genotypes used in this study. Table shows all fly genotypes, descriptions and sources used in this study, grouped by distinct types of transgenes. References are listed in Methods. 